\title{
Extending the Time Domain of Neuronal Silencing with Cryptophyte Anion Channelrhodopsins
}

\author{
Elena G. Govorunova, ${ }^{1}$ Oleg A. Sineshchekov, ${ }^{1}$ Raheleh Hemmati, ${ }^{2}$ Roger Janz, ${ }^{2}$ 'Olivier Morelle, ${ }^{3}$ \\ Michael Melkonian, ${ }^{3}$ Gane K.-S. Wong, ${ }^{4,5}$ and John L. Spudich ${ }^{1}$
}

\section{DOI:http://dx.doi.org/10.1523/ENEURO.0174-18.2018}

${ }^{1}$ Center for Membrane Biology, Department of Biochemistry and Molecular Biology, The University of Texas Health Science Center at Houston, McGovern Medical School, Houston, TX 77030, ${ }^{2}$ Department of Neurobiology and Anatomy, The University of Texas Health Science Center at Houston, McGovern Medical School, Houston, TX 77030, ${ }^{3}$ Institute of Botany, Cologne Biocenter, University of Cologne, Cologne D-50674, Germany, ${ }^{4}$ Departments of Biological Sciences and of Medicine, University of Alberta, Edmonton, AB T6G 2E1, Canada, and ${ }^{5}$ Beijing Genomics Institute-Shenzhen, Shenzhen 518083, China

\section{Visual Abstract}
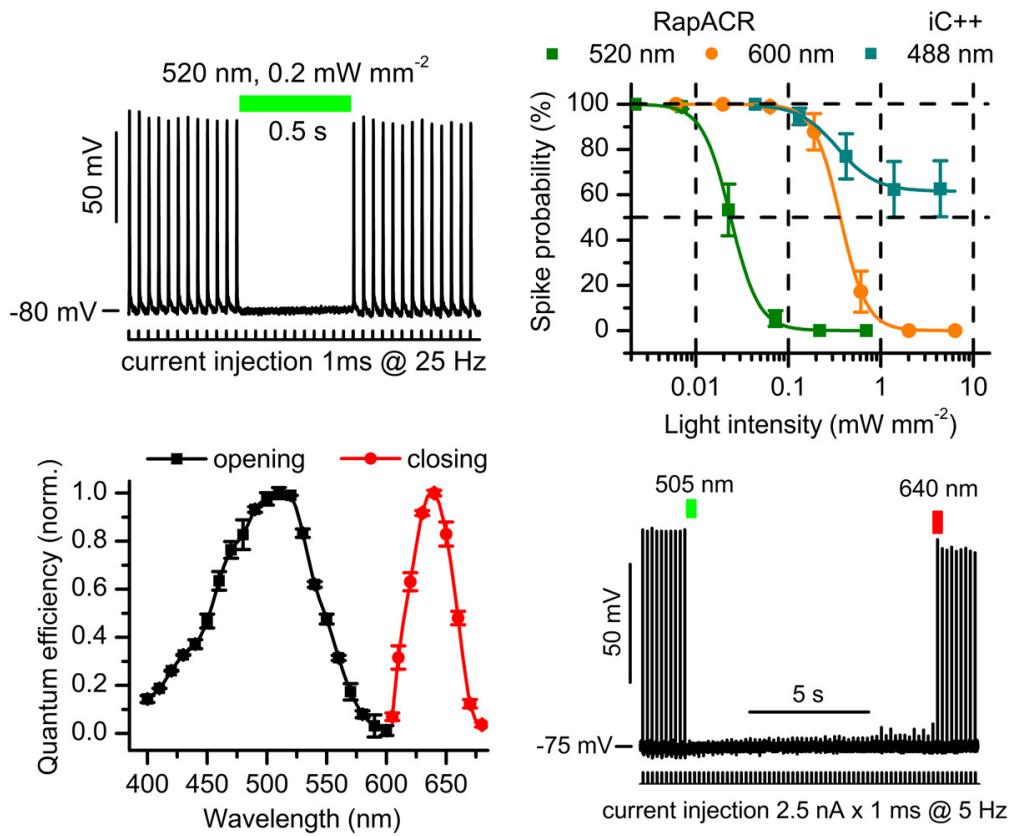

\section{Significance Statement}

We report both fast and slow variants of cryptophyte anion channelrhodopsins (ACRs) that enable efficient neuronal silencing with light in the expanded time window of $10 \mathrm{~ms}$ to tens of seconds. These tools can be used at low expression levels to avoid possible detrimental effects on the physiology of recipient cells and help to minimize light intensities to prevent overheating of the tissue in optogenetic experiments. Their potential applications include analysis of neuronal circuitry, the slow closing channel variant enabling measurements requiring an open channel in the dark amenable to optical imaging, and the development of optogenetic treatments for neurologic diseases involving neuron hyperexcitability. 
Optogenetic inhibition of specific neuronal types in the brain enables analysis of neural circuitry and is promising for the treatment of a number of neurological disorders. Anion channelrhodopsins (ACRs) from the cryptophyte alga Guillardia theta generate larger photocurrents than other available inhibitory optogenetic tools, but more rapid channels are needed for temporally precise inhibition, such as single-spike suppression, of high-frequency firing neurons. Faster ACRs have been reported, but their potential advantages for time-resolved inhibitory optogenetics have not so far been verified in neurons. We report RapACR, nicknamed so for "rapid," an ACR from Rhodomonas salina, that exhibits channel half-closing times below $10 \mathrm{~ms}$ and achieves equivalent inhibition at 50 -fold lower light intensity in lentivirally transduced cultured mouse hippocampal neurons as the secondgeneration engineered $\mathrm{Cl}^{-}$-conducting channelrhodopsin $\mathrm{iC}++$. The upper limit of the time resolution of neuronal silencing with RapACR determined by measuring the dependence of spiking recovery after photoinhibition on the light intensity was calculated to be $100 \mathrm{~Hz}$, whereas that with the faster of the two G. theta ACRs was $13 \mathrm{~Hz}$. Further acceleration of RapACR channel kinetics was achieved by site-directed mutagenesis of a single residue in transmembrane helix 3 (Thr111 to Cys). We also show that mutation of another ACR (Cys to Ala at the same position) with a greatly extended lifetime of the channel open state acts as a bistable photochromic tool in mammalian neurons. These molecules extend the time domain of optogenetic neuronal silencing while retaining the high light sensitivity of Guillardia ACRs.

Key words: channelrhodopsins; chloride ion channels; neuronal inhibition; optogenetics

\section{Introduction}

Control of neuronal activity with genetically targeted molecules (optogenetics) requires both actuators and inhibitors, to de- and hyperpolarize the membrane, respectively (Bernstein et al., 2012; Deisseroth, 2015; Emiliani et al., 2015). Until recently the only optogenetic tools available for inhibition of neuronal spiking had been rhodopsin ion pumps such as halorhodopsin and archaeorhodopsin that transport $\mathrm{Cl}^{-}$in or $\mathrm{H}^{+}$out of the cell, respectively (Zhang et al., 2007; Chow et al., 2010; Chuong et al., 2014). However, the pumps translocate at most only one charge per captured photon and therefore their optogenetic use typically requires high light intensities (10-20 mW mm ${ }^{-2}$; Maurice et al., 2015; Parker et al., 2016; Arguello et al., 2017).

Ion channels form a continuous hydrophilic pore in the lipid bilayer and are therefore much more efficient for manipulation of the membrane potential than ion pumps. Mature neurons maintain a steep inwardly directed $\mathrm{Cl}^{-}$ gradient across their somatic membrane (Price and Trus-

Received May 2, 2018; accepted June 19, 2018; First published June 27, 2018. J.L.S., E.G.G., and O.A.S. are inventors on patents filed by the University of Texas Health Science Center at Houston regarding optogenetic use of natural ACRs. All other authors declare no competing financial interests.

Author contributions: E.G.G., O.A.S., and J.L.S. designed research; O.M., M.M., G.K.-S.W., E.G.G., R.H., and R.J. performed research; E.G.G., O.A.S., and J.L.S. analyzed data; E.G.G., O.A.S., R.H., R.J., O.M., M.M., G.K.-S.W., and J.L.S. wrote the paper.

This work was supported by National Institutes of Health Grants U01MH109146 and R01GM027750, the Hermann Eye Fund, and the Endowed Chair Grant AU-0009 from the Robert A. Welch Foundation.

Acknowledgements: We thank Xin (Faith) Wang and Xiaoqin Liu for technical assistance.

Correspondence should be addressed to John L. Spudich, Center for Membrane Biology, Department of Biochemistry and Molecular Biology, The University of Texas Health Science Center at Houston, McGovern Medical School, 6431 Fannin Street, MSB 6.130, Houston TX 77030. E-mail: john.l.spudich@uth.tmc.edu.

DOI:http://dx.doi.org/10.1523/ENEURO.0174-18.2018

Copyright (C) 2018 Govorunova et al.

This is an open-access article distributed under the terms of the Creative Commons Attribution 4.0 International license, which permits unrestricted use, distribution and reproduction in any medium provided that the original work is properly attributed. sell, 2006; Khirug et al., 2008), so opening of $\mathrm{Cl}^{-}$channels, such as endogenous ionotropic GABA receptors, hyperpolarize the membrane. Therefore, considerable efforts have been invested in converting cation channelrhodopsins (CCRs) from chlorophyte algae into $\mathrm{Cl}^{-}$channels, yielding two principal variants (Berndt et al., 2014; Wietek et al., 2014). Continued engineering efforts resulted in second-generation tools by eliminating their residual permeability for $\mathrm{H}^{+}$(Wietek et al., 2015; Berndt et al., 2016) and modification of their kinetics and spectral sensitivity (Wietek et al., 2017).

Meanwhile, two natural anion channelrhodopsins (ACRs) with unitary conductance that exceeds that of any previously known channelrhodopsins were found in the cryptophyte alga Guillardia theta (Govorunova et al., 2015). These proteins have been shown to require less light than rhodopsin pumps for inhibition of spiking in cultured rodent neurons (Govorunova et al., 2015), and behavioral responses in Caenorhabditis elegans (Bergs et al., 2018) and Drosophila (Mohammad et al., 2017). Furthermore, GtACRs did not produce rebound effects (Wei et al., 2018), observed when using rhodopsin pumps (Chuong et al., 2014; Mahn et al., 2016). GtACR2 enabled neuronal silencing at 20 -fold lower light intensity with 65 -fold better time resolution than that required by the most light-sensitive $\mathrm{Cl}^{-}$-conducting $\mathrm{CCR}$ mutants available at the time (Govorunova et al., 2015), but side-byside comparison of natural ACRs with the secondgeneration engineered silencing tools has yet to be conducted.

Closing of GtACR channels requires tens to hundreds of milliseconds, which limits their temporal precision for silencing of neuronal types that fire at high frequencies. In a screen of natural ACR homologs, a faster molecule, named ZipACR, has been found, but its light sensitivity as a neuronal silencer has not been determined (Govorunova et al., 2017b).

In long-term optogenetic experiments, continuous illumination may lead to considerable heating of the tissue (Wiegert et al., 2017). One possible solution of this prob- 
Table 1. Compositions of pipette and bath solutions and liquid junction potentials in experiments with HEK293 cells

\begin{tabular}{|c|c|c|c|c|c|c|c|c|c|c|}
\hline & $\mathrm{NaCl}$ & $\mathrm{KCl}$ & $\mathrm{CaCl}_{2}$ & $\mathrm{MgCl}_{2}$ & $\mathrm{Na}_{2}$ EGTA & HEPES & Glucose & NaAsp & $\mathrm{pH}$ & LJP \\
\hline Pipette standard & - & 126 & 0.5 & 2 & 5 & 25 & - & - & 7.4 & - \\
\hline Bath standard & 150 & - & 1.8 & 1 & - & 10 & 5 & - & 7.4 & 4.7 \\
\hline Bath Asp & - & 一 & 1.8 & 1 & 一 & 10 & 5 & 150 & 7.4 & -7 \\
\hline
\end{tabular}

Asp, aspartate; EGTA, ethylene glycol tetraacetic acid; HEPES, 4-(2-hydroxyethyl)-1-piperazineethanesulfonic acid; LJP, liquid junction potential. All concentrations are in $\mathrm{mM}$.

lem is to use "step-function tools," i.e., light-gated channels that remain open for seconds after the light is switched off. $\mathrm{Cl}^{-}$-conducting CCR mutants have been converted into such tools (Berndt et al., 2014; Wietek et al., 2014) by mutagenetic disruption of the residues that form the "DC gate" (an interhelical hydrogen bond between Cys128 and Asp156, CrChR2 numbering; Nack et al., 2010). Mutation of the Cys128 homolog in GtACR1 to Ala led to a dramatic decrease in the rates of the second phase of channel closing and decay of the $M$ intermediate of the photocycle (Sineshchekov et al., 2015, 2016). Expression of the GtACR1_C102A mutant in the body wall muscles of $C$. elegans enabled their relaxation on illumination (Bergs et al., 2018), but this mutant had not so far been tested in mammalian neurons.

In this study, we report a new ACR from the cryptophyte alga Rhodomonas salina, nicknamed RapACR, that provides 3-8-fold higher time resolution of neuronal inhibition (depending on the light intensity and membrane voltage) than the previously used GtACR2, while exhibiting a similar light sensitivity. A side-by-side test revealed that RapACR caused the same photoinduced rheobase shift at $\sim 50$ times lower light intensity than the secondgeneration light-gated CCR-derived $\mathrm{Cl}^{-}$channel iC ++ . We found that the C102A mutation increased the light sensitivity of GtACR1 $\sim 7$-fold and permitted rapid restoration of neuronal firing by a pulse of red light. These findings provide strategies for using natural ACRs as inhibitory optogenetic tools and demonstrate their versatility.

\section{Materials and Methods}

\section{Identification of ACR homologs in algal transcriptomes}

ACR homologs were identified by searching over 2000 transcriptomes obtained from two sequencing projects, the MMETS project (Keeling et al., 2014) and 1KP project (Matasci et al., 2014) using probabilistic inference methods based on profile hidden Markov models (profile HMMs) implemented in HMMER software (version 3.1b2; Eddy, 2011). HMM profiles were built from previously known ACR sequences using default parameters and refined on functional testing of ACR homologs by electrophysiological measurements. Search procedures were automated with Python 2.7 and the Biopython module (Cock et al., 2009).

\section{Molecular cloning}

DNA polynucleotides encoding the transmembrane domains of transcripts showing homology to previously known ACRs optimized for human codon usage were synthesized (GenScript) and cloned into the mammalian expression vector pcDNA3.1 (Life Technologies) in frame with an enhanced yellow fluorescent protein (EYFP) tag for expression in human embryonic kidney (HEK293) cells. The sequence information was deposited in GenBank. For expression in neurons, ACR fusion constructs were transferred to the pFUGW vector backbone (Lois et al., 2002). Mutants were generated using QuikChange XL kit (Agilent Technologies) and verified by sequencing. The polynucleotide sequence encoding iC ++ was synthesized (GenScript) according to Berndt et al. (2016), fused to EYFP and cloned in the pcDNA3.1 and pFUGW vectors, as described for cryptophyte ACRs.

\section{HEK293 transfection and recording}

HEK293 cells were transfected using the ScreenFectA transfection reagent (Waco Chemicals USA). All-transretinal (Sigma) was added at the final concentration of 4 $\mu \mathrm{M}$ immediately after transfection. Transfection with each tested ACR variant was repeated at least in three different batches of culture, and the results obtained in cells from all batches were pooled together.

Photocurrents were recorded $48-72 \mathrm{~h}$ after transfection in the whole-cell voltage clamp mode with an Axopatch 200B amplifier (Molecular Devices) using the 2-kHz lowpass Bessel filter. The signals were digitized at $5 \mathrm{kHz}$ with a Digidata 1440A using pClamp 10 software (both from Molecular Devices). Patch pipettes with resistances of 2-5 $\mathrm{M} \Omega$ were fabricated from borosilicate glass. Solution compositions are listed in Table 1. A $4 \mathrm{M} \mathrm{KCl}$ bridge was used in all experiments, and possible diffusion of $\mathrm{Cl}^{-}$from the bridge to the bath was minimized by frequent replacement of the bath solution with fresh buffer. Individual transfected HEK293 cells were selected for patching by inspecting their tag fluorescence; non-fluorescent cells were excluded. Series resistance was periodically checked during recording, and experiments showing $>20 \%$ increase were discarded. Data were also excluded if a gigaohm seal was lost during recording. Cells in which we could not establish a gigaohm seal were automatically excluded from measurements.

Continuous light pulses were provided by a Polychrome $\checkmark$ light source (T.I.L.L. Photonics $\mathrm{GmbH}$ ) at the halfbandwidth $15 \mathrm{~nm}$ in combination with a mechanical shutter (Uniblitz Model LS6, Vincent Associates; half-opening time $0.5 \mathrm{~ms}$ ). The light intensity was attenuated with neutral density filters. The maximal available quantum density at the focal plane of the $40 \times$ objective was measured with a piezo detector and ranged from $4.6(400 \mathrm{~nm})$ to $8.5(470 \mathrm{~nm}) \mathrm{mW} \mathrm{mm} \mathrm{mm}^{-2}$. For measurements of the dependence of photocurrents on the light intensity, the dark interval between subsequent light pulses was $30 \mathrm{~s}$ for all tested variants except the GtACR1_C102X mutants, for which it was $180 \mathrm{~s}$ because of their slow current decay. 
Table 2. Compositions of pipette and bath solutions and liquid junction potentials in experiments with neurons

\begin{tabular}{|c|c|c|c|c|c|c|c|c|c|}
\hline & $\mathrm{K}$ gluconate & $\mathrm{KCl}$ & $\mathrm{NaCl}$ & $\mathrm{CaCl}_{2}$ & $\mathrm{MgCl}_{2}$ & HEPES & Glucose & $\mathrm{pH}$ & LJP \\
\hline Pipette solution & 135 & - & - & - & 2 & - & - & 7.2 & 16.5 \\
\hline Bath Tyrode's solution & - & 2 & 125 & 3 & 1 & 25 & 30 & 7.3 & - \\
\hline
\end{tabular}

HEPES, 4-(2-hydroxyethyl)-1-piperazineethanesulfonic acid; LJP, liquid junction potential. All concentrations are in mM.

For measurements of the action spectra cells were illuminated with short $(50 \mathrm{~ms})$ pulses of monochromatic (halfbandwidth $10 \mathrm{~nm}$ ) light of low intensity within the linear range of the dependence. To avoid possible adaptation during measurements, the spectral sensitivity in each cell was scanned with 10-nm intervals first from the shortest wavelength to the longest and then again in the reversed order.

To determine reversal potentials, we recorded in each cell a series of photocurrent traces in response to 1-s light pulses at the holding potentials changed in $20-\mathrm{mV}$ increments from -60 to $60 \mathrm{mV}$ at the amplifier output. The measurements were repeated first using standard solutions, and then on partial substitution of $\mathrm{Asp}^{-}$for $\mathrm{Cl}^{-}$in the bath (Table 1). One value of the reversal potential was obtained per one cell. All measurements were conducted at room temperature $\left(25^{\circ} \mathrm{C}\right)$.

\section{Lentivirus production, titration, and delivery}

Lentivirus was produced in HEK293FT cells (Invitrogen) by triple-transfection with the plasmids pCMV-VSVG, $\mathrm{p} \Delta 8.9$ and corresponding channelrhodopsin-EYFP fusions in the pFUGW backbone using Lipofectamine 2000 (ThermoFisher). The virus was purified from the medium by ultracentrifugation at $17,000 \mathrm{rpm}$ in an SW32 rotor for $2 \mathrm{~h}$. Viral titers where determined by counting the percentage of fluorescent HEK293 cells in monolayers transduced with serially diluted virus preparations. The titers of concentrated virus were between $3 \times 10^{5}$ and $5 \times 10^{6}$ infectious units $(\mathrm{IU}) / \mathrm{ml}$. Neurons were transduced $1 \mathrm{~d}$ after plating with 10-100 $\mu$ l of concentrated virus per slide to yield $>90 \%$ of neurons to become fluorescent.

\section{Neuronal cultivation and recording}

Mouse hippocampi (strain E18) were purchased from BrainBits, digested by papain to release individual neurons that were then cultured on top of a glia feeder layer in NbActiv4 medium (BrainBits) supplemented with alltrans retinal $(0.4 \mu \mathrm{M})$. BrainBits collects the brains using procedures that are approved by their Institutional Animal Use and Care Committee. Patch clamp measurements were conducted 8-14 d after transduction. The same photoexcitation source and measuring setup was used as described above for HEK293 cells, except that the compositions of solutions were as listed in Table 2.

Individual neurons were randomly selected for patching without inspecting their tag fluorescence. Neurons in which we could not establish a gigaohm seal or those exhibiting $>20 \%$ increase in access resistance during recording were excluded from measurements, as were those in which the seal broke during recording. Spiking was evoked by somatic current injection and recorded in current clamp mode. For measurements of the depen- dence of spiking probability on the light intensity, we injected 1-ms current pulses of $2.5 \mathrm{nA}$. Unless otherwise stated, the frequency of electrical stimulation was $5 \mathrm{~Hz}$, because a subpopulation of rodent pyramidal hippocampal neurons generates high-frequency bursts of spikes on injection of a single short current pulse (Graves et al., 2012), which interferes with spiking probability measurements. At $5-\mathrm{Hz}$ stimulation, the membrane voltage returned to the resting level before injection of each subsequent current pulse in all tested neurons. The duration of illumination was $2 \mathrm{~s}$ for each ACR variant, except the slow mutant GtACR1_C102A, for which it was $17 \mathrm{~s}$. To avoid possible adaptation during measurements of light sensitivity, in each neuron, a series of light pulses was applied with 30-s dark intervals for all tested ACR variants, except GtACR1_C102A, for which the dark interval was $180 \mathrm{~s}$, first from the lowest to the highest intensity and then again in the reversed order. For rheobase measurements neurons were injected with a current ramp $(0-2 \mathrm{nA}, 1 \mathrm{~s})$ in the dark or $500 \mathrm{~ms}$ after the onset of actinic illumination. We found that the rheobase magnitude strongly depended on the duration of cultivation (days after transduction); therefore, neuronal cultures of the matched age were used for comparisons between different rhodopsin variants. For spiking recovery measurements, a single 1-ms current pulse was applied per each recorded trace at an incrementally varied time interval after the end of a 500-ms light pulse. Measurements in each neuron started with injecting current at the time 0, i.e., at the very end of the light pulse. If its spiking was inhibited at the given light intensity, the neuron was repetitively stimulated with an incrementally increased time interval between the light stimulus and current pulse using a 30-s dark adaptation period between subsequent traces.

\section{Immunofluorescence microscopy}

Hippocampal neurons at day 14 post-transduction were fixed in $4 \%$ paraformaldehyde in PBS, washed, permeabilized (0.3\% Triton X-100 in PBS), washed once again, and blocked with $2 \%$ goat serum in PBS for 30 min. The fixed permeabilized neurons were incubated with polyclonal rabbit anti-GFP antibody (1:500; catalog \#132002, Synaptic Systems) and either guinea pig antiMAP2 (microtubule associated protein 2) antibody (1: 1000; catalog \#188004, Synaptic Systems) or mouse antiSV2 (synaptic vesicle glycoprotein 2) antibody (1:100; Registry ID: AB 2315387, Developmental Studies Hybridoma Bank) at $4^{\circ} \mathrm{C}$ overnight. For secondary staining, the preparations were incubated with Alexa Fluor 488conjugated goat anti-rabbit antibody (catalog \#A11034, Invitrogen) and Alexa Fluor 568-conjugated goat antiguinea pig antibody (catalog \#A11075, Invitrogen), or Alexa Fluor 647-conjugated goat anti-mouse antibody 
(catalog \#A21236, Invitrogen) at room temperature for $1 \mathrm{~h}$, after which the samples were washed and mounted with ProLongDiamond Antifade mounting medium (Invitrogen). Images were taken with ZEN software using an LSM 510 META laser scanning microscope (Carl Zeiss). The laser wavelengths were $488 \mathrm{~nm}(\mathrm{KrAr}), 543 \mathrm{~nm}(\mathrm{HeNe})$, and 633 $\mathrm{nm}(\mathrm{HeNe})$. The emission filters LP 650, BP 490-510, and BP 560-615 were used.

\section{Data analysis}

Estimation of mean photocurrent amplitudes, the degree of photocurrent inactivation, electrical charge transferred during illumination, and half-rise and half-decay times

From each cell, one current trace was recorded in the voltage clamp mode, and the baseline measured before illumination was subtracted using Clampfit software (a subroutine of pClamp). The same software was used to measure the peak current amplitude with a cursor, and to measure the stationary amplitude by averaging the data points during the last $100 \mathrm{~ms}$ of illumination. The degree of photocurrent inactivation was calculated by subtraction of the stationary value from the peak value, division by the peak value and multiplication by $100 \%$. The amount of charge transferred across the membrane during illumination was calculated as the area (integral) under the current trace using Clampfit software. The rise and decay of ACR photocurrents are multiexponential (Sineshchekov et al., 2015); therefore, to characterize their kinetics, we calculated the half-rise and half-decay times, rather than their time constants, using Clampfit software. For each patched cell, there was one half-rise and one half-decay value. We averaged the photocurrent amplitude values, the degree of inactivation, the amount of charge and half-rise and half-decay times across all tested cells and calculated the SEM (the reported $n$ values indicate the number of tested cells). The data points obtained in individual cells are shown in the respective figures as empty circles.

\section{Determination of the photocurrent action spectra}

In each cell, a response to illumination at each wavelength was measured at least twice in a symmetrical fashion, as described above. In each trace, the initial slope of photocurrent was assessed from the mean amplitude of the signal recorded during its close to the linear rise, usually during the first $5-15 \mathrm{~ms}$ depending on the current rate. The spectral data sets obtained in all scans (the number of which is indicated in the figure legend) were pooled together (because the differences between individual cells in ACR expression levels or patch parameters were not expected to influence ACR spectral properties), normalized to the maximal value and averaged to produce the mean and SEM values (the reported $n$ values indicate the number of spectral scans). The mean and SEM values were then corrected for quantum density measured for each wavelength. The positions of the spectral maxima were determined using B-spline approximation of the data points in Origin 7 (OriginLab Corporation).

\section{Calculation of the reversal potentials}

In each current trace from a series measured at incremental holding voltages as described above, we calculated the peak value, as described above, transferred the obtained values to Origin 7 software and plotted them against the holding potential values corrected for liquid junction potentials calculated using the Clampex built-in LJP calculator (Barry, 1994). The reversal potential $\left(E_{r e v}\right.$; the value at which the line connecting the data points crossed the $x$-axis) was determined using Origin software. The value obtained in the standard bath was then subtracted from that in the Asp- bath thus yielding the value of the $\mathrm{E}_{\text {rev }}$ shift caused by Asp ${ }^{-}$substitution. For each cell, one value of the $E_{\text {rev }}$ shift was obtained. The shift values were averaged across cells to produce the mean and SEM values (the reported $n$ values indicate the number of tested cells). The data points obtained in individual cells are shown as empty circles.

\section{Determination of spiking probability}

Spiking probability was determined by counting the number of fully developed spikes (with the amplitude $>95 \%$ of that in the dark) during 2-s illumination periods using Clampfit software. For each neuron, the numbers of spikes during two illumination periods of the same intensity applied in a symmetrical fashion, as described above, were summarized, divided by the total number of applied electrical pulses (20) and multiplied by $100 \%$. The intensity of half-inhibition for the slow GtACR1_C102A mutant was calculated using the last $2 \mathrm{~s}$ of the 17 -s light pulse. For each light intensity, one percentage value was obtained for each neuron. The data were then averaged across all neurons to produce the mean and SEM values (the reported $n$ values indicate the number of tested neurons). Logistic functions were then fit to the data sets measured at each wavelength using Origin software.

\section{Rheobase measurements}

Rheobase values (the amplitude of injected current at the start of the first evoked spike) were measured from the recorded traces with a cursor using Clampfit software. A single value was obtained for each tested light intensity in each neuron. Then the data were averaged across all neurons to produce the mean and SEM values (the reported $n$ values indicate the number of tested neurons).

\section{Spiking recovery analysis}

For each neuron, a single series of traces was recorded for each tested light intensity, as described above. For comparison of the recovery times in neurons transfected with RapACR and GtACR2, only neurons for which $1 \%$ was the minimal light intensity that fully inhibited spiking were selected. The spike amplitude at each time point in each trace was measured using Clampfit software. The data were averaged across neurons to produce the mean and SEM values (the reported $n$ values indicate the number of tested cells) and plotted against time using Origin software. After that, the value of the half-recovery time at each intensity was calculated for each neuron, averaged across neurons to produce the mean and SEM values (the reported $n$ values indicate the number of tested cells) and plotted against the light intensity.

\section{Image analysis}

To quantify RapACR membrane targeting, lines were drawn through the center of cell images, and the fluorescence density profiles were calculated and analyzed using ImageJ 1.51j8 (National Institutes of Health). Primary den- 
Table 3. Protein name abbreviations, GenBank accession numbers, source organisms, transcript names, and maxima of photocurrents action spectra of ACR homologs tested in this study

\begin{tabular}{|c|c|c|c|c|c|}
\hline \# & $\begin{array}{l}\text { Protein name } \\
\text { abbreviation }\end{array}$ & Accession & Organism & $\begin{array}{l}\text { Transcript } \\
\text { name }\end{array}$ & $\begin{array}{l}\text { Spectral } \\
\max .(\mathrm{nm})\end{array}$ \\
\hline 1 & C1ACR_561 & MG831198 & Chroomonas sp. (CCMP2293) & CAMNT 0022335561* & N/A \\
\hline 2 & GcACR_197 & MG831184 & Geminigera cryophila (CCMP2564) & CAMNT 0021184197* & N/A \\
\hline 3 & GcACR_201 & MG831185 & Geminigera cryophila (CCMP2564) & CAMNT $0021188201^{*}$ & N/A \\
\hline 4 & HpACR_213 & MG831186 & Hanusia phi (CCMP325) & CAMNT 0009606213* & N/A \\
\hline 5 & HaACR_359 & MG831187 & Hemiselmis andersenii (CCMP1180) & CAMNT 0009587359* & N/A \\
\hline 6 & HrACR_495 & MG831188 & Hemiselmis rufescens (PCC563) & CAMNT $0014430495^{*}$ & N/A \\
\hline 7 & PsuACR_353 & MG831189 & Proteomonas sulcata (CCMP704) & CAMNT 0026606353* & 520 \\
\hline 8 & RaACR_687 & MG831190 & Rhodomonas abbreviata (Caron Lab isolate) & CAMNT $0023412687^{*}$ & 520 \\
\hline 9 & RIACR_497 & MG831191 & Rhodomonas lens (RHODO) & CAMNT 0019250497* & 520 \\
\hline 10 & RapACR/RsACR_665 & MG831192 & Rhodomonas salina (CCMP1319) & CAMNT $0012765665^{*}$ & 520 \\
\hline 11 & R1ACR_653 & MG831193 & Rhodomonas sp. (CCMP768) & CAMNT 0049478653* & 470 \\
\hline 12 & R1ACR_6367 & MG831194 & Rhodomonas sp. (CCMP768) & CAMNT $0049496367^{*}$ & 480 \\
\hline 13 & R2ACR_041 & MG831197 & Rhodomonas sp. (CCAC1630) & IAYV-2051041 \# & N/A \\
\hline
\end{tabular}

* Transcripts from the MMETS project.

\# Transcripts from the 1KP project.

A

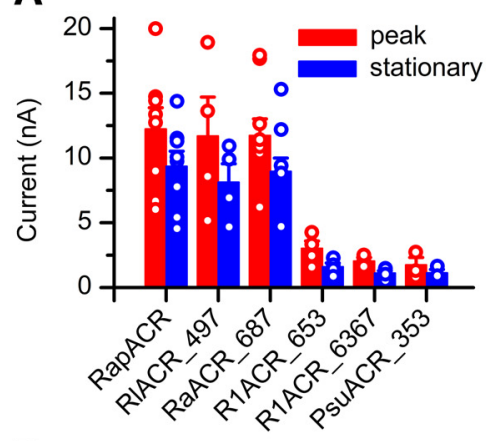

D

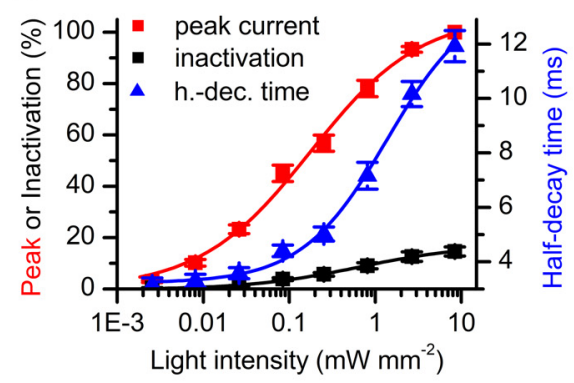

B

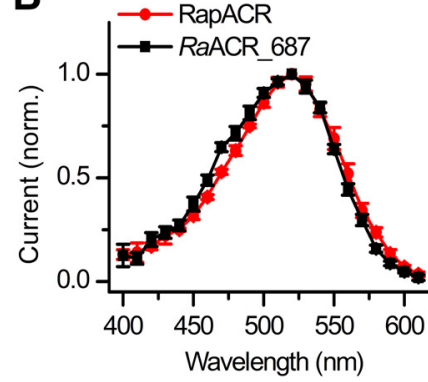

E

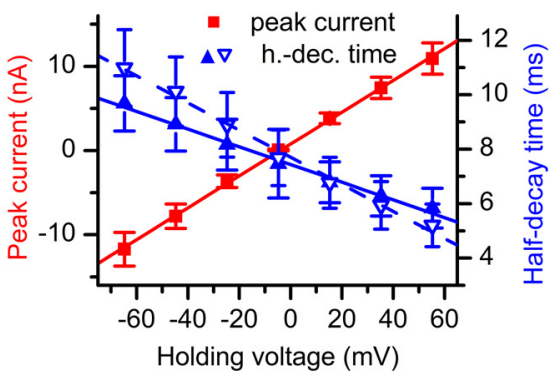

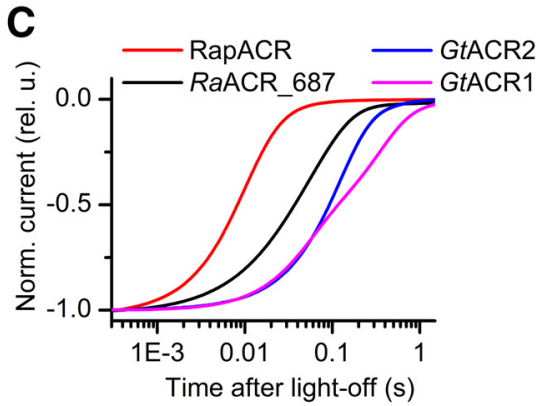

$\mathbf{F}$

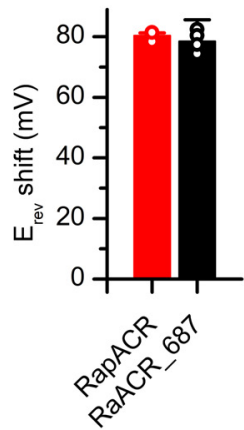

Figure 1. Screening of ACR homologs. A, The amplitude of photocurrents generated by tested ACR homologs expressed in HEK293 cells in response to the first pulse of continuous light at the wavelength of the maximal sensitivity for each homolog (Table 3 ) at -60 $\mathrm{mV}$ at the amplifier output in standard solutions. The stationary current was measured at the end of a 1-s light pulse. The data are the mean values \pm SEM $(n=3-10$ cells). The data obtained in each individual cell are shown as empty circles. $\boldsymbol{B}$, The action spectra of photocurrents generated by RapACR (RsACR_665) and RaACR_687. The data are the mean values \pm SEM ( $n=4$ and $n=8$ scans, respectively). $\boldsymbol{C}$, The kinetics of the photocurrent decay after switching off the continuous light (1-s duration) at $-60 \mathrm{mV}$. $\boldsymbol{D}, \mathrm{The}$ dependence of the normalized peak amplitude, inactivation, and half-decay time of RapACR photocurrents recorded in response to 1 -s pulses of $520-n m$ light on the stimulus intensity. The data points are mean \pm SEM ( $n=5$ cells). $\boldsymbol{E}$, The dependence of the peak amplitude (red) and half-decay time (blue) of RapACR photocurrents on the holding voltage corrected for the liquid junction potential. Filled symbols, solid lines, measurements using standard HEK293 solutions (Table 1); empty downward triangles, dashed line, measurements using neuronal solutions (Table 2). The data points are mean \pm SEM $(n=6$ cells). $\boldsymbol{F}$, The shifts of the reversal potential on partial replacement of $\mathrm{Cl}^{-}$with Asp ${ }^{-}$in the bath. The data are the mean values \pm SEM $(n=3$ and $n=5$ cells for RapACR and RaACR_687, respectively). 
A
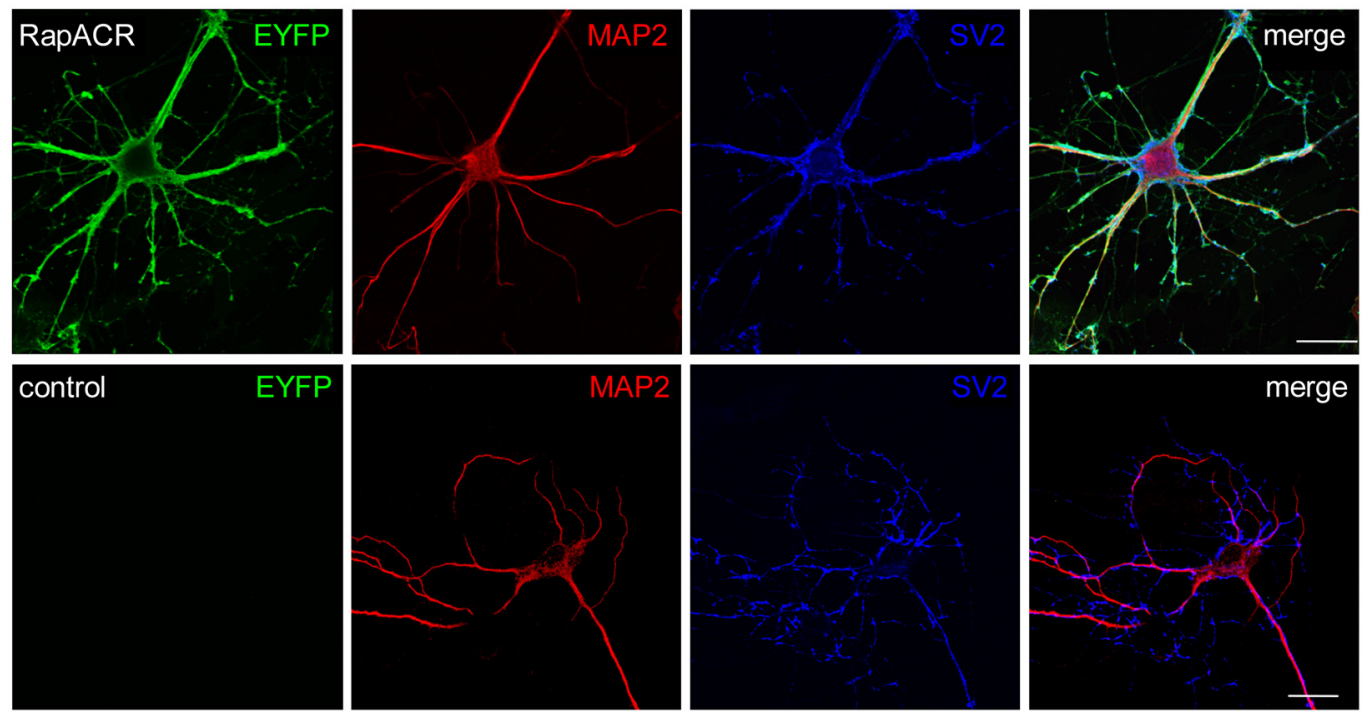

B
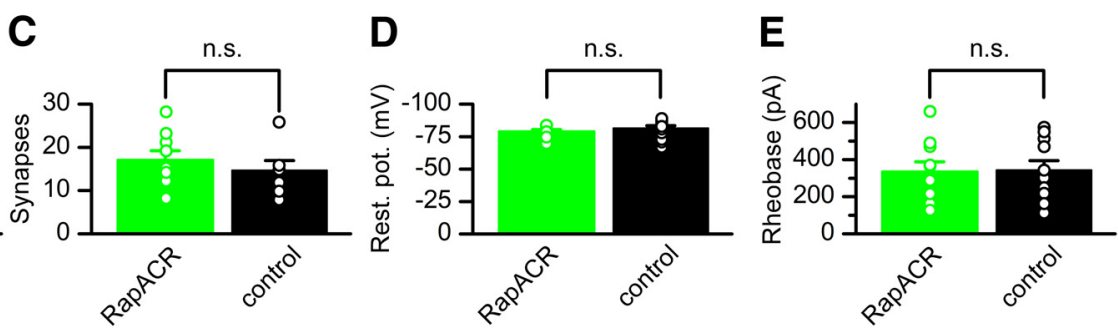

Figure 2. RapACR expression does not change morphologic and physiologic parameters of neurons. $\boldsymbol{A}$, Immunofluorescent images of neurons transduced with RapACR_EYFP fusion (top row) or control (non-transduced) neurons (bottom row) and stained with antibodies against EYFP (green channel), MAP2 (microtubule associated protein 2) as the dendrite marker (red channel), and SV2 (synaptic vesicle protein 2) as the synapse marker (blue channel). Scale bar, $20 \mu \mathrm{m}$. $\boldsymbol{B}$, $\boldsymbol{C}$, The number of dendrites per neuron and synapses per dendritic length of $20 \mu \mathrm{m}$, respectively. The data points are mean \pm SEM $(n=10$ and $n=7$ cells for RapACR and control, respectively). $\boldsymbol{D}, \boldsymbol{E}$, The resting potential (abbreviated as rest. pot. on the $y$-axis in panel $\boldsymbol{D}$ ) and rheobase in the dark. The data points are mean \pm SEM ( $n=9$ and $n=13$ cells for RapACR and control, respectively, tested $8-14 \mathrm{~d}$ after transduction). Statistical significance was tested by the Mann-Whitney test.

drites from randomly selected neurons were identified as MAP2-positive branches originating from the soma and crossing the circumference of the $70-\mu \mathrm{m}$ radius. Synapses (identified by SV2 staining) were quantified using Carl Zeiss ZEN microscope software in five randomly picked dendritic stretches (length, $20 \mu \mathrm{m}$ ) and averaging them for each neuron. From each neuron, one average dendrite number and one synapse number were derived, after which these numbers were averaged across all neurons.

\section{Sample size determination}

The sample size was estimated from previous experience, as recommended by the NIH guidelines (Dell et al., 2002).

\section{Randomization}

We presume that animals sacrificed for isolation of neurons were randomly selected by BrainBits. HEK293 and neuronal cultures were randomly assigned to experimental groups.

\section{Statistics}

Statistical analysis was performed using IBM SPSS Statistics software, and the selection of statistical tests was based on previously published studies. Normality and equal variances of the data were not assumed, and therefore non-parametric statistical tests were used; $p>0.05$ was considered not significant. For pairwise comparisons of independent data sets the two-sided Mann-Whitney test was used, and for comparisons of multiple independent data sets, the Kruskal-Wallis test with Bonferroni correction (the similarity of distributions was assessed by visual inspection of a boxplot). When no specific statistical hypothesis was tested, descriptive statistics was reported as mean \pm SEM values. The error bars show the SEM values.

\section{Accession codes}

GenBank accession codes of ACRs first reported in this article are listed in Table 3.

\section{Data availability}

All data are available from the authors on reasonable request. Plasmids carrying functional ACR expression constructs are available through the nonprofit DNA distributor Addgene.

\section{Results}

\section{Screening of ACR homologs}

To explore the diversity of the ACR protein family and in search of better tools for optogenetics, we identified 13 new ACRs homologs in ongoing algal transcriptome sequencing projects (Keeling et al., 2014; Matasci et al., 
A $\quad 520 \mathrm{~nm}, 0.08 \mathrm{~mW} \mathrm{~mm}{ }^{-2}$

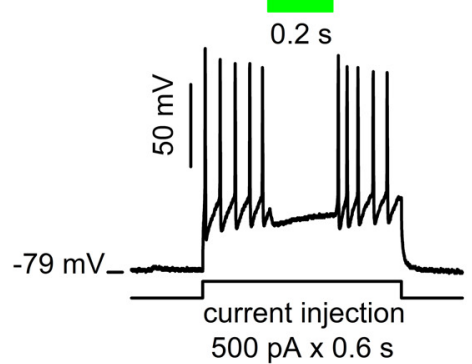

C $\quad 520 \mathrm{~nm}, 0.2 \mathrm{~mW} \mathrm{~mm}^{-2}$

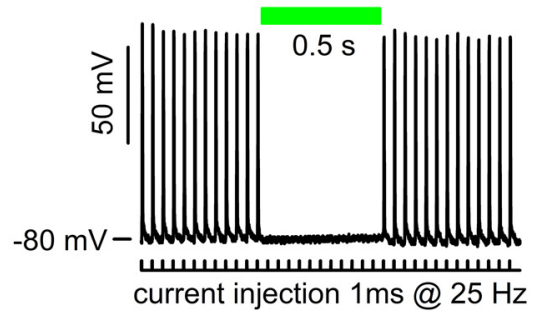

E

$520 \mathrm{~nm}, 0.08 \mathrm{~mW} \mathrm{~mm}^{-2}$

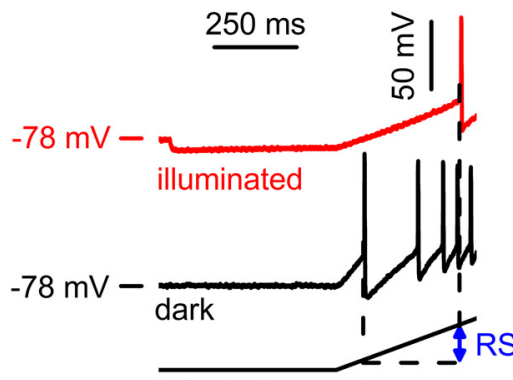

injected current
B

$520 \mathrm{~nm}, 7.3 \mathrm{~mW} \mathrm{~mm}{ }^{-2}$
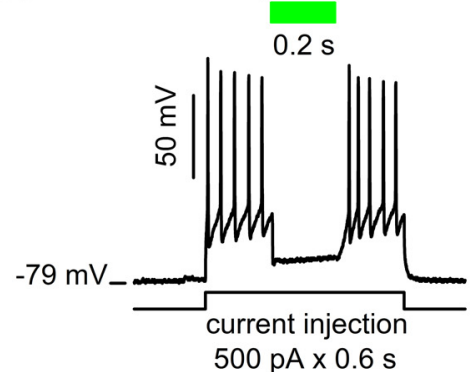

RapACR iC++

D $520 \mathrm{~nm}$ - $600 \mathrm{~nm}$ - $488 \mathrm{~nm}$

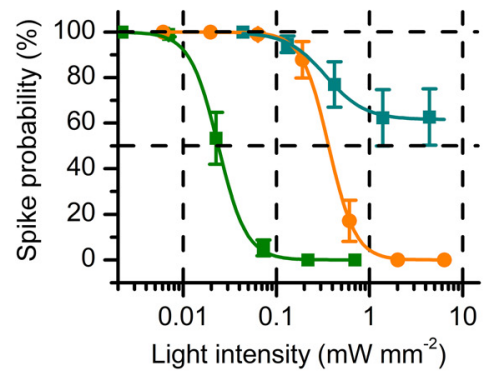

$\mathbf{F}$

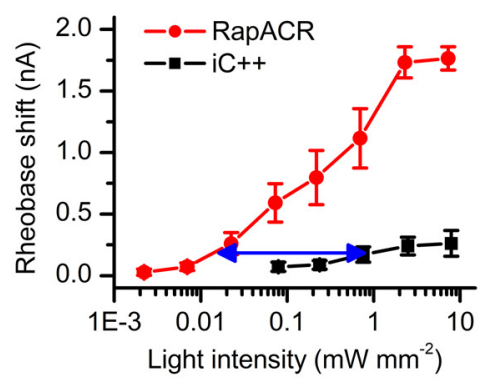

Figure 3. RapACR is more efficient for neuronal silencing than the second-generation engineered $\mathrm{Cl}^{-}$-conducting channelrhodopsin $\mathrm{iC}++$. $\boldsymbol{A}, \boldsymbol{B}$, Photoinhibition of spiking in a neuron expressing RapACR at two different light intensities. Spiking was induced by depolarization of the membrane by prolonged current injection as shown at the bottom. The time course of illumination is shown as green bars on top. C, A representative voltage trace recorded from a neuron expressing RapACR and stimulated with a train of 1-ms pulses of $2.5 \mathrm{nA}$ delivered at $25 \mathrm{~Hz}$. Passive response of the membrane (recorded under complete inhibition of spiking with light) was digitally subtracted. The time course of illumination is shown as a green bar. $\boldsymbol{D}$, The dependence of neuronal inhibition on the light intensity for RapACR and iC ++ photoactivated at different wavelengths. The data points are mean \pm SEM $(n=15$ and $n=14$ neurons for RapACR and $\mathrm{iC}++$, respectively) approximated with a logistic function; fitting parameters are listed in Table 4. $\boldsymbol{E}$, Voltage traces recorded from a neuron transduced with RapACR and stimulated with a depolarizing current ramp (0-2 nA, $1 \mathrm{~s}$; bottom trace) injected $500 \mathrm{~ms}$ after the onset of illumination (red) or in the dark (black). The blue arrow shows the photoinduced rheobase shift (RS). $\boldsymbol{F}$. The dependence of the rheobase shift on the light intensity in neurons transduced with RapACR or iC ++ . The current ramp was from 0 to $2 \mathrm{nA}$ in $1 \mathrm{~s}$. The blue arrow shows the difference in the light sensitivity between the two tested channels. The data points are mean $\pm \operatorname{SEM}(n=9$ and $n=6$ neurons for RapACR and iC ++ , respectively).

Table 4. Numerical parameters of logistic function fitting to the light sensitivity data

\begin{tabular}{llllllll}
\hline Figure & Dataset & $\mathrm{x}_{0}$ & $\mathrm{x}_{0}$ error & $p$ & $p$ error & Chi $^{2} / \mathrm{DoF}$ & $R^{2}$ \\
$3 B$ & RapACR @ 520 nm & 0.02376 & 0.00041 & 2.86833 & 0.22156 & 1.47822 & 0.99949 \\
$3 B$ & RapACR @ 600 nm & 0.36375 & 0.00229 & 3.05385 & 0.03368 & 0.11346 & 0.99996 \\
$3 B$ & iC++ @ 488 nm & 0.33928 & 0.02383 & 2.0744 & 0.27267 & 1.57038 & 0.99746 \\
$6 D$ & GtACR1_C102A & 0.00047 & 0.00002 & 1.05893 & 0.04073 & 2.29911 & 0.99822 \\
$6 D$ & GtACR1 & 0.00299 & 0.00021 & 1.51384 & 0.14325 & 0.00101 & 0.99251 \\
N/A & GtACR2 @ 470 nm & 0.02948 & 0.00176 & 2.00325 & 0.23583 & 10.68705 & 0.99553 \\
N/A & ZipACR @ 520 nm & 3.2183 & 0.31733 & 1.47268 & 0.20552 & 19.85807 & 0.98616
\end{tabular}


Table 5. Numbers of independent tests ( $n$ values)

\begin{tabular}{lll}
\hline Figure & Variant & $n$ \\
$1 A$ & RsACR_665 & 8 \\
& RIACR_497 & 4 \\
& RaACR_687 & 10 \\
& R1ACR_653 & 4 \\
& R1ACR_6367 & 5 \\
& PsuACR_353 & 3 \\
$6 B$ & GtACR1 & 12 \\
& GtACR1_C102T & 13 \\
& GtACR1_C102S & 7 \\
$7 E$ & GtACR1_C102A & 3 \\
& RaACR_687 & 10 \\
& R2ACR_142 & 12 \\
& RapACR & 5 \\
& ZipACR & 5 \\
& RaACR_687_T107A & 6 \\
& R2ACR_142_C102A & 5 \\
& RapACR_T111A & 7 \\
$7 F$ & ZipACR_C119A & 5 \\
& RaACR_687_T107A & 6 \\
& R2ACR_142_C102A & 7 \\
& RapACR_T111A & 7 \\
\hline & ZipACR_C119A &
\end{tabular}

2014), synthesized human codon-adapted polynucleotides encoding their transmembrane domains and expressed the resultant constructs in HEK293 cells as inframe C-terminal EYFP fusions. The GenBank accession numbers, source organisms, transcript names, and protein names abbreviated by the first letters of the genus and species names and three or four last digits of the transcript codes are listed in Table 3.

Six of the tested homologs generated photocurrents in HEK293 cells. For three of the functional homologs, RsACR_665, RIACR_497, and RaACR_687, the mean peak current amplitude recorded at $-60 \mathrm{mV}$ with standard solutions (131 and $156 \mathrm{mM} \mathrm{Cl}^{-}$in the pipette and bath, respectively; for other components, see Table 1) was $>10$ $\mathrm{nA}$, whereas the other three homologs generated modest to small photocurrents (Fig. 1A). Although RsACR_665 and RIACR_497 were isolated from different algal species, their protein sequences differed only at three residue positions. Therefore, RIACR_497 was excluded from further analysis.

The spectral sensitivity of ACR homologs was determined by measuring the initial slope of current responses to 50-ms light pulses in the linear range of the intensity dependence, as described in Materials and Methods. Both RsACR_665 and RaACR_687 exhibited the spectral maxima at $520 \mathrm{~nm}$ (Fig. 1B); the spectral maxima for other homologs are listed in Table 3 . The current decay kinetics after switching off the light was faster for both proteins than for GtACRs, and for RsACR_665, faster than for RaACR_687 (Fig. 1C). The current decay of RsACR_665 further accelerated on reducing the light intensity or shifting the voltage to more depolarized values (Fig. 1D,E). We nicknamed RsACR_665 "RapACR" to reflect its rapid channel kinetics.

To test the channels for permeability for $\mathrm{Cl}^{-}$, this ion in the bath was partially replaced with non-permeable aspartate, and a shift of the reversal potential $\left(E_{\text {rev }}\right)$ was determined by measuring the current-voltage dependencies, as described in Materials and Methods. On such replacement, the $E_{\text {rev }}$ shifted to more positive values following the $\mathrm{E}_{\mathrm{Cl}}$ (Fig. $1 F$ ), as has been shown for GtACRs (Govorunova et al., 2015). This observation confirmed that RapACR and RaACR_687 are anion-selective channels, as suggested by their sequence homology with earlier known cryptophyte ACRs.

\section{Comparison of RapACR with the second-generation $\mathrm{Cl}^{-}$-conducting $\mathrm{CCR}$ mutant iC++}

To compare RapACR with the second-generation $\mathrm{Cl}^{-}$conducting CCR mutant iC ++ (Berndt et al., 2016) as optogenetic inhibitors, we expressed each construct under the ubiquitin promoter of the pFUGW vector (Lois et al., 2002) in cultured mouse hippocampal neurons using lentiviral delivery. RapACR showed predominantly plasma membrane localization (Fig. $2 A$ ). The ratio of the tag fluorescence in the plasma membrane to that in the cytoplasm was $13.9 \pm 6.9$ (mean \pm SEM, $n=9$ neurons). RapACR expression changed neither morphologic nor

Table 6. Results of independent-samples Mann-Whitney tests

\begin{tabular}{|c|c|c|c|c|c|c|c|c|c|}
\hline Figure & Variant & Total & $\begin{array}{l}\text { Mann- } \\
\text { Whitney } U\end{array}$ & Wilcoxon W & $\begin{array}{l}\text { Test } \\
\text { statistic }\end{array}$ & SE & $\begin{array}{l}\text { Standard test } \\
\text { statistic }\end{array}$ & $\begin{array}{l}\text { Asymptotic } \\
\text { Significance } \\
\text { (two-sided test) }\end{array}$ & $\begin{array}{l}\text { Exact Significance } \\
\text { (two-sided test; } \\
p \text { value) }\end{array}$ \\
\hline \multirow[t]{4}{*}{$4 E$} & $0.2(0.3)$ & 18 & 80.000 & 116.000 & 80.000 & 10.865 & 3.682 & 0.000 & 0.000 \\
\hline & $0.7(0.8)$ & 18 & 80.000 & 116.000 & 80.000 & 11.179 & 3.578 & 0.000 & 0.000 \\
\hline & $2.3(2.7)$ & 18 & 80.000 & 116.000 & 80.000 & 11.050 & 3.620 & 0.000 & 0.000 \\
\hline & $7.3(8.5)$ & 18 & 80.000 & 116.000 & 80.000 & 10.978 & 3.644 & 0.000 & 0.000 \\
\hline $5 D$ & & 16 & 17.000 & 53.000 & 17.000 & 9.522 & -1.575 & 0.115 & 0.130 \\
\hline $6 C$ & & 25 & 152.000 & 230.000 & 152.000 & 18.385 & 4.025 & 0.000 & 0.000 \\
\hline \multirow[t]{4}{*}{2} & $B$ & 17 & 20.000 & 48.000 & 20.000 & 10.190 & -1.472 & 0.141 & 0.161 \\
\hline & $C$ & 17 & 29.000 & 57.000 & 29.000 & 10.197 & -0.588 & 0.556 & 0.601 \\
\hline & $D$ & 22 & 43.500 & 134.500 & 43.500 & 14.941 & -1.004 & 0.315 & 0.324 \\
\hline & $E$ & 22 & 74.500 & 165.500 & 74.500 & 14.971 & 1.069 & 0.285 & 0.292 \\
\hline \multirow[t]{4}{*}{8} & $B$ & 41 & 186.500 & 339.500 & 186.500 & 37.247 & 0.470 & 0.638 & 0.668 \\
\hline & $C$ & 41 & 212.000 & 365.000 & 212.000 & 37.649 & 0.212 & 0.832 & 0.870 \\
\hline & $D$ & 23 & 57.000 & 148.000 & 57.000 & 16.069 & -0.498 & 0.619 & 0.648 \\
\hline & $E$ & 23 & 67.000 & 158.000 & 67.000 & 16.125 & 0.124 & 0.901 & 0.927 \\
\hline
\end{tabular}


Table 7. Results of independent-samples Kruskal-Wallis test with Bonferroni correction

\begin{tabular}{llllll}
\hline Figure & Variant & Test statistics & SE & Standardized test statistics & Significance \\
$6 B$ & C102T vs Wild type & -12.500 & 4.102 & -3.047 & 0.002 \\
& C102S vs Wild type & -13.500 & 3.637 & -3.712 & 0.000 \\
& C102A vs Wild type & -18.500 & 4.936 & -3.748 & 0.000 \\
\hline
\end{tabular}
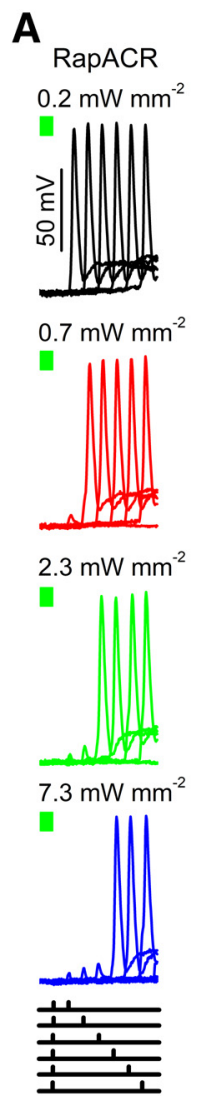

current injection $2.5 \mathrm{nA} \times 1 \mathrm{~ms}$

$8.5 \mathrm{~mW} \mathrm{~mm}^{-2}$
B GtACR2

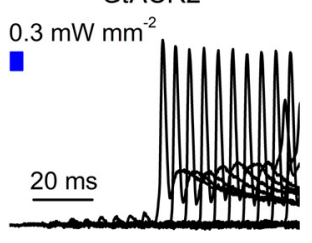

$0.8 \mathrm{~mW} \mathrm{~mm}^{-2}$

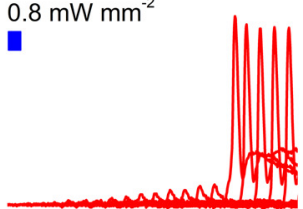

$2.7 \mathrm{~mW} \mathrm{~mm}^{-2}$

口.
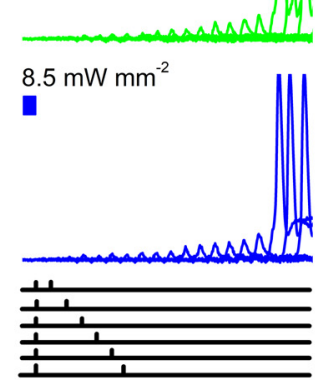

C
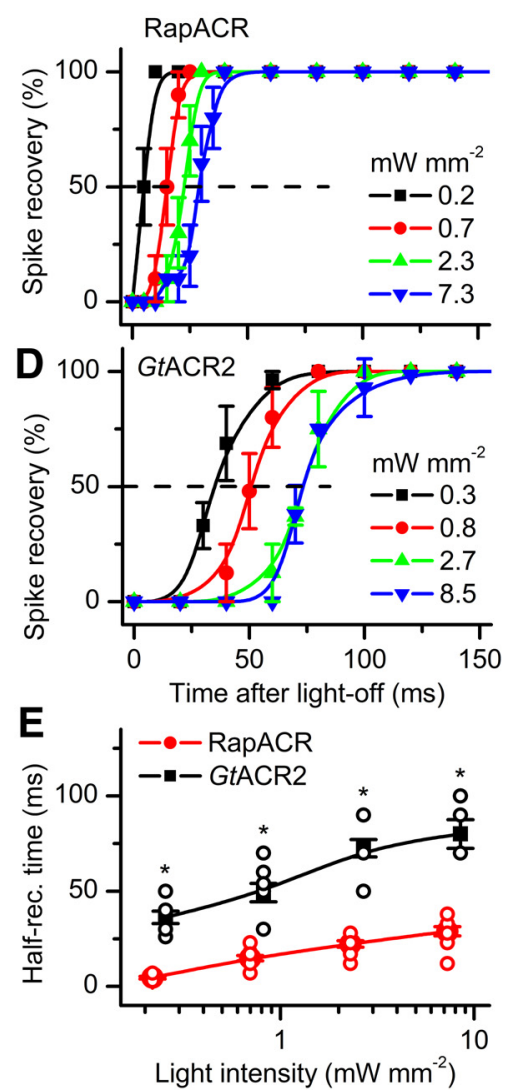

Figure 4. Using RapACR improves temporal resolution of neuronal silencing. $\boldsymbol{A}, \boldsymbol{B}$, Representative series of overlaid voltage traces recorded from neurons expressing RapACR or GtACR2, respectively, illuminated for $500 \mathrm{~ms}$ (the end of the light pulse is shown as a colored bar on top) at 520 or $470 \mathrm{~nm}$, respectively, and stimulated with injection of a pair of 1-ms current pulses, the first of which was applied at the end of illumination, and the second of which, at an incrementally increased time after switching off the light (the injection protocols are schematically drawn at bottom; for GtACR2, only the first six protocols are shown). Passive response of the membrane (recorded under complete inhibition of spiking with light) was digitally subtracted. $\boldsymbol{C}, \boldsymbol{D}$, The time course of recovery of spiking after illumination measured as shown in panels $\boldsymbol{A}, \boldsymbol{B}$ for cells that could be inhibited with $1 \%$ light intensity. The data points are the mean values \pm SEM ( $n=10$ and $n=8$ neurons for RapACR and GtACR2, respectively). $\boldsymbol{E}$, The dependence of the time of $50 \%$ recovery of spiking on the light intensity calculated from the same cells as in $\boldsymbol{C}, \boldsymbol{D} ; * p<0.001$ (pairwise comparison of RapACR and GtACR2 data at each intensity by the Mann-Whitney test). Data obtained in each individual neuron are shown as empty circles.

physiologic parameters of neurons in the dark, as compared to control (non-transfected) neurons (Fig. 2B-E).

When tested in voltage clamp mode at the $\mathrm{Cl}^{-}$gradient typical for the neuronal soma (4 and $135 \mathrm{mM} \mathrm{Cl}^{-}$in the pipette and bath, respectively; for other solution components, see Table 2), RapACR generated hyperpolarizing photocurrents at the holding voltages above the $\mathrm{E}_{\mathrm{Cl}}(\sim-90$ $\mathrm{mV}$ ). Expression of RapACR in neurons enabled optical inhibition of their spiking (Fig. $3 A-C$ ). To determine the light sensitivity of optogenetic inhibition, virally transduced neurons were selected without regard to their tag fluorescence amplitude and stimulated by pulsed current.
The probability of spiking (i.e., the percentage of current pulses that resulted in a spike) was measured in the dark and during illumination at various wavelengths and intensities. When activated at the wavelength of their maximal spectral sensitivity (520 and $470 \mathrm{~nm}$, respectively), RapACR required similar energy densities to inhibit neurons as the earlier used GtACR2 (Fig. 3D, olive; Table 4). Furthermore, spiking in RapACR neurons could be completely inhibited even with 600-nm light (i.e., a wavelength $80 \mathrm{~nm}$ longer than the RapACR absorption maximum; Fig. $3 D$, orange). Among neurons transduced with $\mathrm{iC}++$ and illuminated at the wavelength of its maximal sensitivity 
A
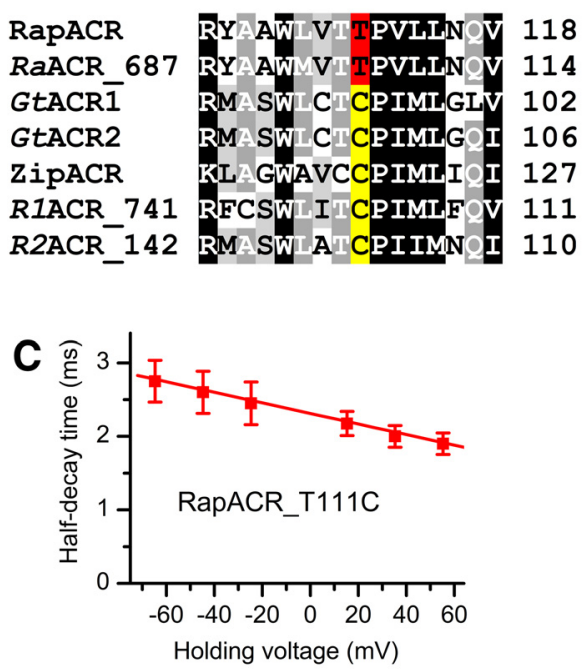

B

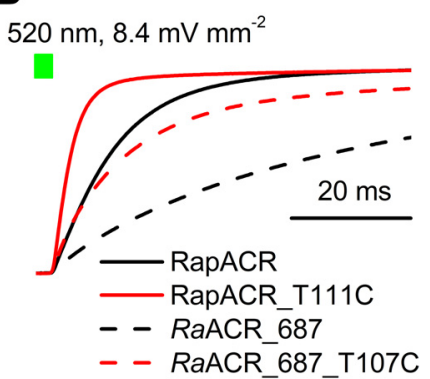

D

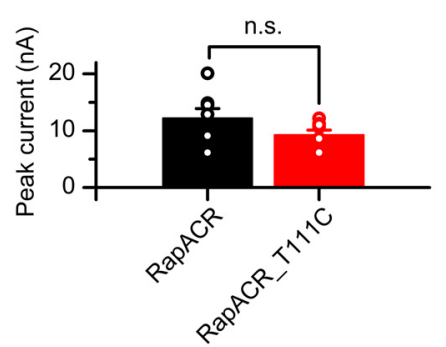

Figure 5. Characterization of the fast RapACR_T111C and RaACR_687_T107C mutants. A, A ClustalW alignment of the $3^{d}$ transmembrane helix around the Cys-128 position (CrChR2 numbering) from indicated ACRs. The Thr residues found in this position are highlighted red, Cys residues, yellow. B, Normalized photocurrent decay after 1-s illumination recorded from wild-type RapACR (black, solid) and RaACR_687 (black, dashed), and the corresponding T111C (red, solid) and T107C (red, dashed) mutants. C, The dependence of the half-decay time of RapACR_T111C photocurrent on the holding voltage corrected for the liquid junction potential. The data points are the mean \pm SEM $(n=4$ cells). $\boldsymbol{D}$, Peak photocurrent amplitude at $-60 \mathrm{mV}$. The wild-type data are from Figure $1 A$, the data for RapACR_T111C are the mean values \pm SEM $(n=8$ cells). Statistical significance was tested by the Mann-Whitney test. The values obtained in individual cells are shown as open circles.

(488 nm), spiking was inhibited only in those with the brightest tag fluorescence, even at the highest light intensity tested. The mean data for $\mathrm{iC}++$ neurons are shown in Figure $3 D$, dark cyan. We also measured the photoinduced rheobase shifts in neurons transduced with $\mathrm{Ra}-$ pACR or $\mathrm{iC}++$, as shown by the blue arrow in Figure $3 E$ for RapACR. The half-maximal shift detected with $\mathrm{iC}++$ was reached with RapACR at $\sim 50$-fold lower light intensity $\left(\sim 0.01 \mathrm{~mW} \mathrm{~mm}^{-2}\right.$; Fig. $3 F$, blue arrow).

\section{Using RapACR improves the time resolution of photoinhibition}

GtACR2 has been shown to suppress spiking in neurons in vitro and in vivo at light intensities lower than those required by rhodopsin pumps and $\mathrm{Cl}^{-}$conducting CCR mutants (Govorunova et al., 2015; Mohammad et al., 2017; Bergs et al., 2018). However, its photocurrent decays with a time constant of $\sim 40$ ms (Govorunova et al., 2015), which is too slow for temporally precise inhibition (e.g., single spike suppression) of neurons firing at high frequencies. The performance of a faster variant, ZipACR, as a neuronal silencer has only been tested at the maximal light intensity (Govorunova et al., 2017b), and its light sensitivity remained unknown. We transduced neurons with the same amount of ZipACR virus as used for RapACR and measured the sensitivity to photoinhibition of randomly picked neurons without inspecting their tag fluorescence, as described in the previous section. We found that the sensitivity for ZipACR was $\sim 135$-fold less than that for RapACR (Table 4). Thus, although ZipACR exhibits a faster channel decay than RapACR, its lower sensitivity decreases its utility as an optogenetic silencing tool as compared to RapACR.

The rate of membrane repolarization after switching off the light depends not only on the rate of channel closing, but also on the photocurrent amplitude, both of which are light dependent. We measured the light intensity dependence of the time required for spiking recovery after photoinhibition for RapACR and GtACR2. Most rodent hippocampal neurons cannot be repetitively stimulated at frequencies higher than $50 \mathrm{~Hz}$, although they are capable of generating short high-frequency bursts of spikes (Graves et al., 2012). To determine accurately the time required for the recovery of spiking after photoinhibition mediated by ACRs, we injected a pair of depolarizing current pulses per trace. The first pulse was applied precisely at the end of illumination to test whether spiking was inhibited at each particular light intensity. The second was injected at an incrementally varied time after switching off the light to test for spiking recovery. Figure $4 A, B$ shows representative series of overlaid voltage traces recorded from neurons expressing RapACR or GtACR2, respectively. In both cases, the rate of recovery depended on the light intensity. Although the mean light sensitivities of neurons transduced with RapACR or GtACR2 were similar (Table 4), there was variability between individual cells. Therefore, for more accurate comparison of the recovery rates in neurons transduced with RapACR or GtACR2, we selected only those neurons that required approximately the same threshold light intensity $(1 \%$ of 
A

$515 \mathrm{~nm}, 1 \mathrm{~s}, 7.7 \mathrm{~mW} \mathrm{~mm}^{-2}$

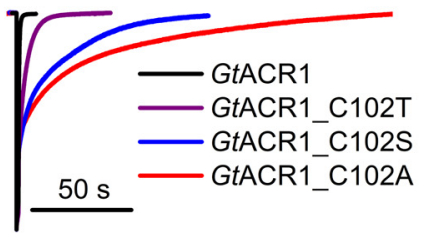

E

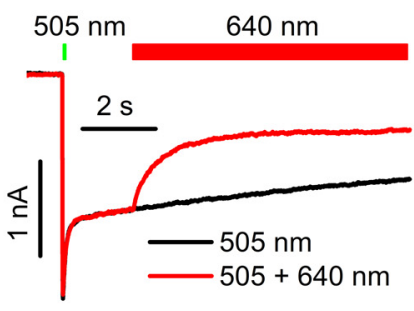

B

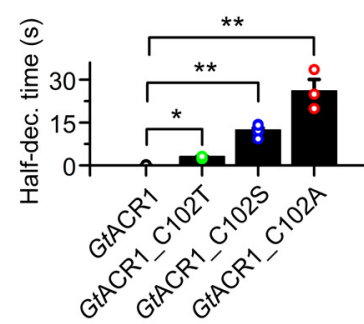

C

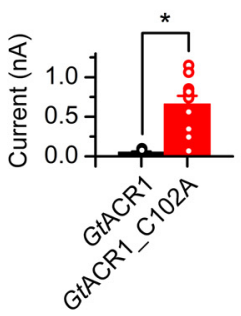

F

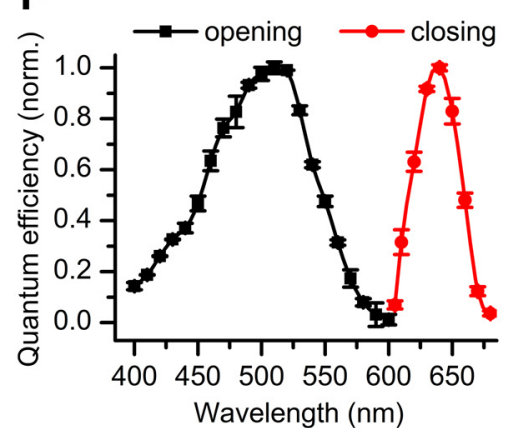

D

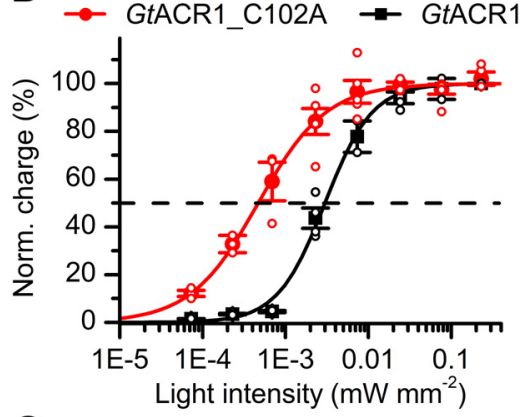

G

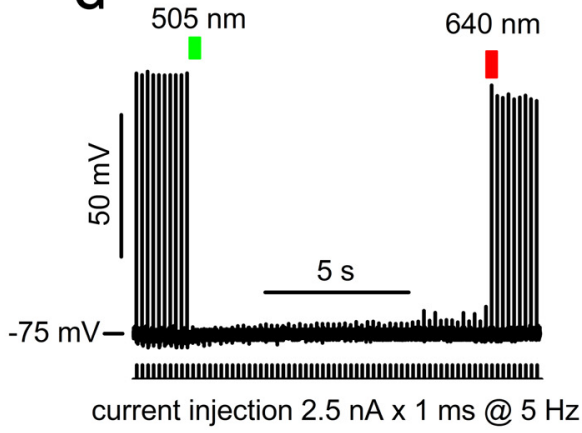

Figure 6. Characterization of the GtACR1_C102X mutants and the use of GtACR1_C102A as a bistable photochromic silencing tool. $\boldsymbol{A}$, Normalized photocurrent traces recorded at $-60 \mathrm{mV}$ in HEK293 cells. $\boldsymbol{B}$, The half-time of the slow decay phase. The data are mean \pm SEM $(n=4-12$ cells; for exact numbers, see Table 5); $* p<0.05, * * p=0.01$; Kruskal-Wallis test with Bonferroni correction. $\boldsymbol{C}$, The amplitudes of stationary photocurrents in HEK293 cells at $-60 \mathrm{mV}$ after 200 -s illumination. The wavelengths were 515 and $505 \mathrm{~nm}$ for GtACR1 and GtACR1_C102A, respectively. The data are mean \pm SEM $(n=13$ and $n=12$ cells, respectively); $* p<0.001$; Mann-Whitney test; see Table 6 for full statistics. $\boldsymbol{D}$, The dependence of electrical charge transferred across the membrane during 100-s illumination at $-60 \mathrm{mV}$. The data are mean \pm SEM $(n=5$ and $n=6$ cells for GtACR1 and GtACR1_C102A, respectively). The fitting parameters are listed in Table 4. E, Opening and partial closing of GtACR1_C102A with light at -60 mV. $\boldsymbol{F}$, The action spectra of GtACR1_C102A opening and closing. The data points are mean \pm SEM ( $n=8$ scans). G, Bidirectional optical control of neuronal spiking with GtACR1_C102A. Passive response of the membrane (recorded under complete inhibition of spiking with light) was digitally subtracted. In panels $\boldsymbol{B}-\boldsymbol{D}$, also the data obtained in each individual cell are shown as empty circles.

the maximum) of inhibition. Figure $4 C, D$ shows the time course of spiking recovery for such neurons, and Figure $4 E$, the dependence of the half-recovery time on the light intensity. RapACR enabled faster recovery than GtACR2 at all tested light intensities. At the lowest light intensity sufficient for silencing, RapACR enabled complete restoration of spiking already at $10 \mathrm{~ms}$ after switching off the light, whereas with GtACR2, 80 ms was required.

\section{Mutagenetic alteration of ACR photocurrent kinetics}

In RapACR and RaACR_687, the position of Cys-102 (GtACR1 numbering) is occupied with Thr (Fig. 5A). Replacement of this residue (Thr111) with Cys in RapACR led to acceleration of the current decay (Fig. 5B, red solid line), so that at the positive voltages its half-time approached $2 \mathrm{~ms}$ (Fig. 5C) matching that of ZipACR, the fastest so far found wild-type ACR (Govorunova et al., 2017b). The peak current amplitude of the T111C mutant was not significantly different from that of the wild-type RapACR (Fig. 5D). The corresponding T107C mutation in RaACR_687 also accelerated the current decay (Fig. 5B, red dashed line) from $\mathrm{t}_{1 / 2} 35 \pm 4 \mathrm{~ms}$ in the wild type ( $n=$ 10 cells) to $12 \pm 3 \mathrm{~ms}$ in the mutant ( $n=5$ cells).

Instead of precise light control in the ms time domain, some optogenetic experiments require prolonged inhibi- tion after a short light pulse. It has been shown that substitution of Cys102 in GtACR1 with Ala leads to a dramatic extension of the second phase of the photocurrent decay (Sineshchekov et al., 2015). On stimulation with continuous light pulses, the amplitude of the slow decay phase in the GtACR1_C102A mutant was 50\% at the maximal intensity (Fig. $6 A$, red), whereas at low light intensities this phase dominated the decay. Mutagenetic replacement of Cys102 with Thr or Ser caused a lesser effect than replacement with Ala (Fig. $6 A, B$; see Table 7 for full statistics). At $0.2 \mu \mathrm{W} \mathrm{mm} \mathrm{m}^{-2}$, the $\mathrm{C} 102 \mathrm{~A}$ mutant generated $\sim 13$ times larger stationary currents than the wild type (Fig. 6C). For 100-s illumination, the C102A mutant required approximately seven times less light than the wild type to reach the half-saturating level of charge transfer (Fig. 6D). Illumination with red light caused partial closing of the GtACR1_C102 channel (Fig. 6E). The action spectrum of channel opening (Fig. 6F, black) corresponded to the absorption spectrum of GtACR1_C102A expressed and purified from Pichia (Sineshchekov et al., 2016) and was slightly blue-shifted from that of the wildtype (the maximum at 505 vs $515 \mathrm{~nm}$ ). The action spectrum of channel closing peaked at $640 \mathrm{~nm}$ (Fig. 6F, red).

Replacement of Thr111 with Ala in RapACR slowed the current decay, as did the corresponding C102 mutation in 
A

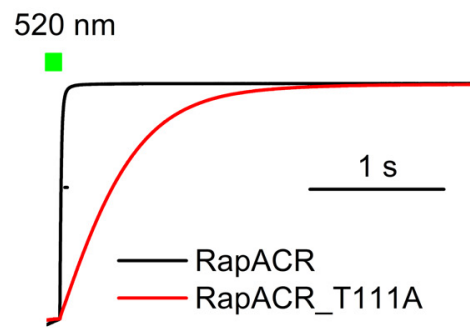

D

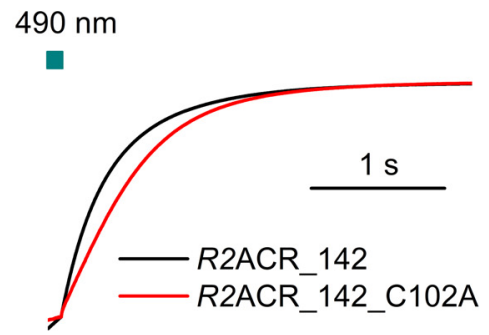

B

$520 \mathrm{~nm}$

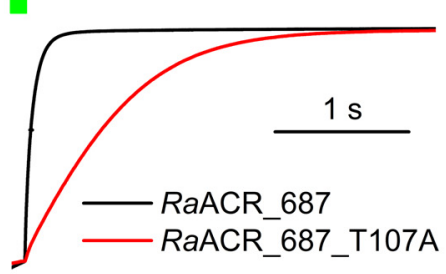

E

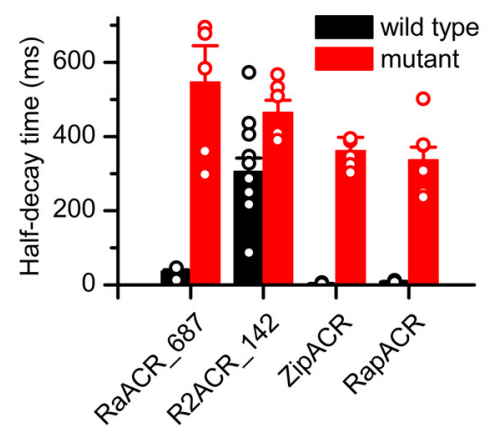

C

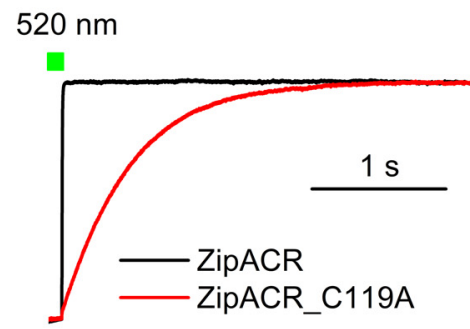

$\mathbf{F}$

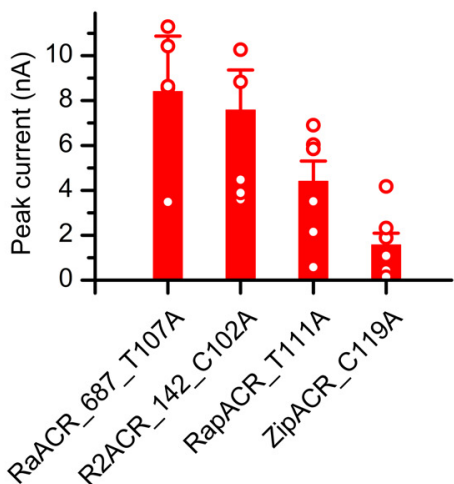

Figure 7. Biophysical characteristics of slow ACR mutants. $\boldsymbol{A}-\boldsymbol{D}$, Normalized photocurrent decay after 1-s illumination recorded from wild-type ACRs (black) and their respective mutants in which the residue homologous to Cys-102 (GtAR1 numbering) was mutated to Ala (red). $\boldsymbol{E}, \boldsymbol{F}$, Photocurrent half-decay times $(\boldsymbol{E})$ and peak photocurrent amplitudes $(\boldsymbol{F})$ measured in wild-type ACRs and their indicated mutants. The data points are mean \pm SEM $(n=5-12$ cells; for exact numbers, see in Table 5).

GtACR1, but the effect was much less pronounced (Fig. $7 A)$. We also tested the corresponding Ala replacement mutants in RaACR_687 and two other ACRs that generate large photocurrents, ZipACR and R2ACR_142 (Govorunova et al., 2017b). The results (Fig. $7 B-F$ ) show that although the mutation led to an extension of the decay time in all tested mutants, none of them exhibited slower decay than the GtACR1_C102A mutant. Therefore, we used the latter to inhibit neuronal spiking. We cloned GtACR1_C102A in the same vector backbone as used for wild-type ACRs and expressed it in cultured mouse hippocampal neurons by lentiviral delivery. No changes in morphologic or physiologic parameters of neurons in the dark were detected on GtACR1_C102A expression (Fig. 8). A brief light pulse of green ( $505 \mathrm{~nm}$ ) light was sufficient to inhibit neuronal spiking for at least $10 \mathrm{~s}$ after switching the light off (Fig. 6G). In neurons transduced with GtACR1_C102A, spiking was rapidly restored with a pulse of red $(640 \mathrm{~nm})$ light (Fig. 6G).

\section{Discussion}

Both natural and engineered $\mathrm{Cl}^{-}$-conducting channelrhodopsins can be considered as silencing tools more physiologic than rhodopsin pumps, since they "shunt" the membrane potential to the $E_{\mathrm{CI}}$ (which in most neurons is close to the resting potential), and therefore prevent nonphysiologic changes in the intracellular $\mathrm{Cl}^{-}$concentration, which have been reported when using the $\mathrm{Cl}^{-}$pump halorhodopsin (Raimondo et al., 2012; Alfonsa et al., 2015).
We show that the light sensitivity of some cryptophyte ACRs as neuronal silencers exceeds not only that of rhodopsin pumps (Govorunova et al., 2015; Mohammad et al., 2017; Bergs et al., 2018) but also that of improved, second-generation engineered $\mathrm{Cl}^{-}$-conducting channelrhodopsins, which makes cryptophyte ACRs the most efficient silencing tools available. When tested side-byside, RapACR enabled complete silencing of neurons at a wavelength $110 \mathrm{~nm}$ more red-shifted than that of the peak absorbance of $\mathrm{iC}++$, at which the latter tool failed to suppress spiking in $>50 \%$ of randomly picked neurons (Fig. 3D). Engineered $\mathrm{Cl}^{-}$-conducting channelrhodopsins have recently been referred to as "engineered ACRs" (eACRs) in the literature (Wietek et al., 2017), but this term is misleading, because chlorophyte CCRs from which they were derived differ from natural cryptophyte ACRs not only in the mutated positions, but form a structurally distinct protein family (Govorunova et al., 2017b).

So far, studies using GtACRs as optogenetic inhibitors of behavior have been conducted in worms (Bergs et al., 2018; Xu et al., 2018), flies (Mauss et al., 2017; Mohammad et al., 2017; Steck et al., 2018), zebrafish (Mohamed et al., 2017), and mouse (Mahn et al., 2017; Forli et al., 2018; Li et al., 2018; Mardinly et al., 2018; Wei et al., 2018). ACRs are also expected to enable silencing of all those types of mammalian neurons in which inhibition has been demonstrated with engineered light-gated $\mathrm{Cl}^{-}$conducting channels (Wietek et al., 2015; Berndt et al., 2016; lyer et al., 2016; Kim et al., 2016; Takahashi et al., 

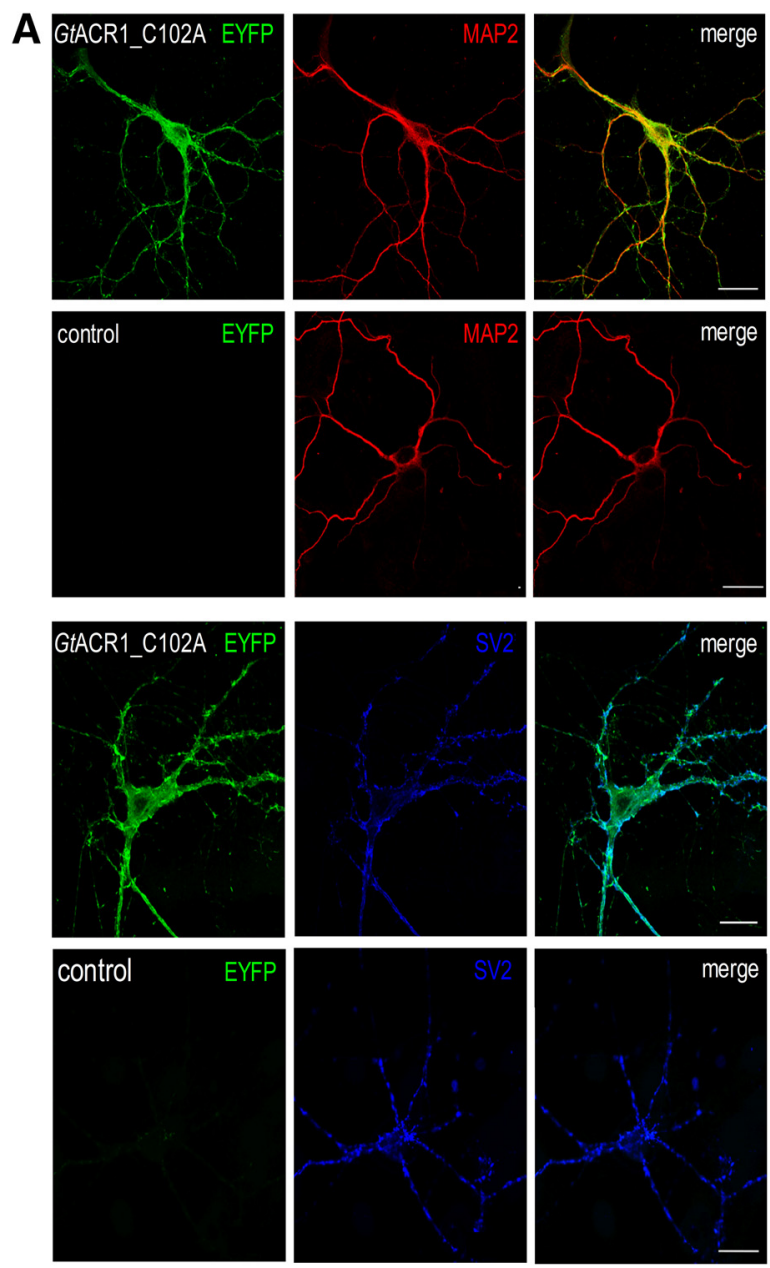

B

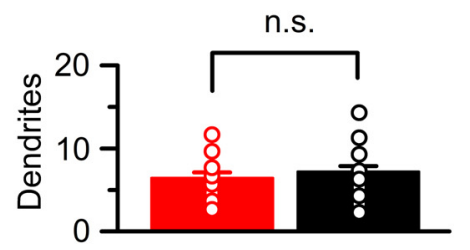

C

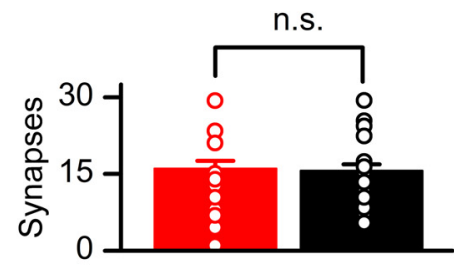

D

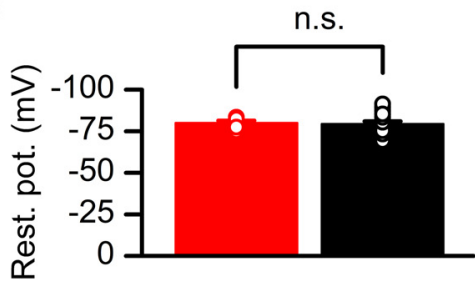

E

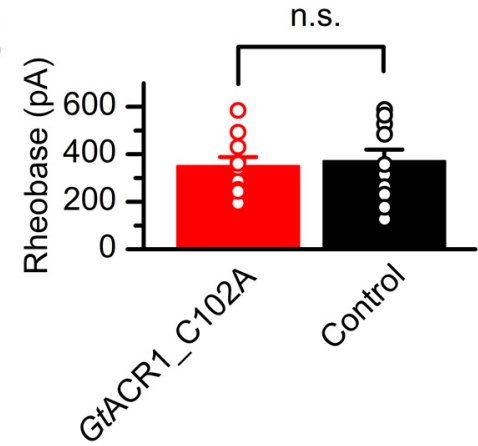

Figure 8. GtACR1_C102A expression does not change morphologic and physiologic parameters of neurons. $\boldsymbol{A}$, Immunofluorescent images of neurons transduced with GtACR1_EYFP fusion (odd rows) or control (non-transduced) neurons (even rows) and stained with antibodies against EYFP (green channel), MAP2 (microtubule associated protein 2) as the dendrite marker (red channel), and SV2 (synaptic vesicle protein 2) as the synapse marker (blue channel). Scale bar, $20 \mu \mathrm{m}$. $\boldsymbol{B}, \boldsymbol{C}$, The number of dendrites per neuron and synapses per dendritic length of $20 \mu \mathrm{m}$, respectively. The data points are mean \pm SEM $(n=17$ and $n=24$ cells for GtACR1_C102A and control, respectively). $\boldsymbol{D}, \boldsymbol{E}$, The resting potential (abbreviated as rest. pot. on the $y$-axis in panel $\boldsymbol{D}$ ) and rheobase in the dark. The data points are mean \pm SEM ( $n=10$ and $n=13$ cells for GtACR1_C102A and control, respectively, tested 8-14 d after transduction). Statistical significance was tested by the Mann-Whitney test (see full results in Table 6).

2016; Chung et al., 2017) and possibly many more. Switching to highly conductive natural ACRs as optogenetic silencing tools will help to: (1) minimize light intensities and thus prevent overheating of the tissue; and (2) decrease expression levels to avoid possible detrimental effects on the physiology of recipient cells, as compared to other available tools.

The kinetics of channel closing of GtACRs enables single-spike suppression in neurons firing at moderate rates (Govorunova et al., 2015) but limits temporal precision of spike suppression in neurons spiking at high frequencies. Faster natural ACRs that generate comparably large photocurrents, such as ZipACR (Govorunova et al., $2017 b)$ or RapACR reported here, are capable of singlespike suppression even in high-frequency firing neurons. The theoretically estimated upper limit of firing frequency at which precise neuronal silencing with ZipACR is pos- sible is $200 \mathrm{~Hz}$, which, however, has not yet been confirmed experimentally (Govorunova et al., 2017b). Although ZipACR and RapACR generated equally large photocurrents in HEK293 cells (Govorunova et al., 2017b; and this study, respectively), ZipACR required much more light to inhibit cultured mammalian neurons than RapACR or GtACR2 (Table 4). The latter observation is consistent with the data obtained in $C$. elegans muscles, where the performance of ZipACR was also inferior to that of GtACR2 (Bergs et al., 2018). This discrepancy between the results obtained with the same tool in different cell types emphasizes the importance of cell-specific tool testing.

The limit for silencing with RapACR that we determined by measuring the recovery rate at the minimal light intensity sufficient to fully suppress spiking is at least $100 \mathrm{~Hz}$ (Fig. 4), and this number may be an underestimate, be- 
cause we measured the recovery only in 5-ms time increments. Further acceleration of ACR channel kinetics, and thereby, a further increase in temporal precision of inhibition, can be achieved by site-directed mutagenesis, as we show here for the RapACR_T111C mutant (Fig. 5). Importantly, fast cryptophyte ACRs permit temporally precise neuronal silencing at low light intensities, in contrast to rhodopsin pumps that also generate fast photocurrents but require strong light. However, when temporally precise photoinhibition using ACRs is needed, it is important to take into consideration that the time required for spiking recovery after photoinhibition depends on the light intensity and is minimal at the minimal intensity sufficient to suppress spiking (Fig. 4E). Improved temporal resolution can also be achieved by reducing ACR expression level (although this will also lead to reduction of the light sensitivity).

ACRs with dramatically extended channel opening time could be engineered to boost their light sensitivity and convert them to step-function tools (Fig. 6). Despite only partially overlapping residue conservation patterns between ACRs and CCRs (Govorunova et al., 2017a), the C102 position in GtACR1 (corresponding to Cys128 in CrChR2) appears to be a common regulator of channel kinetics in both channelrhodopsin families. GtACR1_ C102A functions as a bistable photochromic stepfunction tool for spike inhibition as does CrChR2_C128A for spike generation.

Natural ACRs and their mutants reported here enable efficient neuronal silencing on time scales both shorter and longer than that currently available, which widens the range of potential applications of these powerful optogenetic silencing tools.

\section{References}

Alfonsa $\mathrm{H}$, Merricks EM, Codadu NK, Cunningham MO, Deisseroth K, Racca C, Trevelyan AJ (2015) The contribution of raised intraneuronal chloride to epileptic network activity. J Neurosci 35: 7715-7726. CrossRef Medline

Arguello AA, Richardson BD, Hall JL, Wang R, Hodges MA, Mitchell MP, Stuber GD, Rossi DJ, Fuchs RA (2017) Role of a lateral orbital frontal cortex-basolateral amygdala circuit in cue-induced cocaine-seeking behavior. Neuropsychopharmacology 42:727735. CrossRef Medline

Barry PH (1994) JPCalc, a software package for calculating liquid junction potential corrections in patch-clamp, intracellular, epithelial and bilayer measurements and for correcting junction potential measurements. J Neurosci Methods 51:107-116. Medline

Bergs A, Schultheis C, Fischer E, Tsunoda SP, Erbguth K, Husson SJ, Govorunova EG, Spudich JL, Nagel G, Gottschalk A, Liewald JF (2018) Rhodopsin optogenetic toolbox v2.0 for light-sensitive excitation and inhibition in Caenorhabditis elegans. PLoS One 13:e0191802. CrossRef

Berndt A, Lee SY, Ramakrishnan C, Deisseroth K (2014) Structureguided transformation of channelrhodopsin into a light-activated chloride channel. Science 344:420-424. CrossRef Medline

Berndt A, Lee SY, Wietek J, Ramakrishnan C, Steinberg EE, Rashid AJ, Kim H, Park S, Santoro A, Frankland PW, lyer SM, Pak S, Ährlund-Richter S, Delp SL, Malenka RC, Josselyn SA, Carlén M, Hegemann P, Deisseroth K (2016) Structural foundations of optogenetics: determinants of channelrhodopsin ion selectivity. Proc Natl Acad Sci USA 113:822-829. CrossRef Medline

Bernstein JG, Garrity PA, Boyden ES (2012) Optogenetics and thermogenetics: technologies for controlling the activity of targeted cells within intact neural circuits. Curr Opin Neurobiol 22:61-71. CrossRef Medline

Chow BY, Han X, Dobry AS, Qian X, Chuong AS, Li M, Henninger MA, Belfort GM, Lin Y, Monahan PE, Boyden ES (2010) Highperformance genetically targetable optical neural silencing by light-driven proton pumps. Nature 463:98-102. CrossRef Medline Chung S, Weber F, Zhong P, Tan CL, Nguyen TN, Beier KT, Hörmann N, Chang WC, Zhang Z, Do JP, Yao S, Krashes MJ, Tasic B, Cetin A, Zeng H, Knight ZA, Luo L, Dan Y (2017) Identification of preoptic sleep neurons using retrograde labelling and gene profiling. Nature 545:477-481. CrossRef Medline

Chuong AS, Miri ML, Busskamp V, Matthews GA, Acker LC, Sørensen AT, Young A, Klapoetke NC, Henninger MA, Kodandaramaiah SB, Ogawa M, Ramanlal SB, Bandler RC, Allen BD, Forest CR, Chow BY, Han X, Lin Y, Tye KM, Roska B, et al. (2014) Noninvasive optical inhibition with a red-shifted microbial rhodopsin. Nat Neurosci 17:1123-1129. CrossRef Medline

Cock PJ, Antao T, Chang JT, Chapman BA, Cox CJ, Dalke A, Friedberg I, Hamelryck T, Kauff F, Wilczynski B, de Hoon MJ (2009) Biopython: freely available Python tools for computational molecular biology and bioinformatics. Bioinformatics 25:14221423. CrossRef Medline

Deisseroth K (2015) Optogenetics: 10 years of microbial opsins in neuroscience. Nat Neurosci 18:1213-1225. CrossRef Medline

Dell RB, Holleran S, Ramakrishnan R (2002) Sample size determination. ILAR J 43:207-213. Medline

Eddy SR (2011) Accelerated profile HMM searches. PLoS Comput Biol 7:e1002195. CrossRef Medline

Emiliani V, Cohen AE, Deisseroth K, Häusser M (2015) All-optical interrogation of neural circuits. J Neurosci 35:13917-13926. CrossRef Medline

Forli A, Vecchia D, Binini N, Succol F, Bovetti S, Moretti C, Nespoli F, Mahn M, Baker CA, Bolton MM, Yizhar O, Fellin T (2018) Twophoton bidirectional control and imaging of neuronal excitability with high spatial resolution in vivo. Cell Rep 22:3087-3098. CrossRef Medline

Govorunova EG, Sineshchekov OA, Liu X, Janz R, Spudich JL (2015) Natural light-gated anion channels: a family of microbial rhodopsins for advanced optogenetics. Science 349:647-650. CrossRef Medline

Govorunova EG, Sineshchekov OA, Li H, Spudich JL (2017a) Microbial rhodopsins: diversity, mechanisms, and optogenetic applications. Annu Rev Biochem 86:845-872. CrossRef

Govorunova EG, Sineshchekov OA, Rodarte EM, Janz R, Morelle O, Melkonian M, Wong GK-S, Spudich JL (2017b) The expanding family of natural anion channelrhodopsins reveals large variations in kinetics, conductance, and spectral sensitivity. Sci Rep 7:43358. CrossRef

Graves AR, Moore SJ, Bloss EB, Mensh BD, Kath WL, Spruston N (2012) Hippocampal pyramidal neurons comprise two distinct cell types that are countermodulated by metabotropic receptors. Neuron 76:776-789. CrossRef Medline

lyer SM, Vesuna S, Ramakrishnan C, Huynh K, Young S, Berndt A, Lee SY, Gorini CJ, Deisseroth K, Delp SL (2016) Optogenetic and chemogenetic strategies for sustained inhibition of pain. Sci Rep 6:30570. CrossRef Medline

Li Y, Zeng J, Zhang J, Yue C, Zhong W, Liu Z, Feng Q, Luo M (2018) Hypothalamic circuits for predation and evasion. Neuron 97:911924. CrossRef Medline

Keeling PJ, Burki F, Wilcox HM, Allam B, Allen EE, Amaral-Zettler LA, Armbrust EV, Archibald JM, Bharti AK, Bell CJ, Beszteri B, Bidle KD, Cameron CT, Campbell L, Caron DA, Cattolico RA, Collier JL, Coyne K, Davy SK, Deschamps P, et al. (2014) The Marine Microbial Eukaryote Transcriptome Sequencing Project (MMETSP): illuminating the functional diversity of eukaryotic life in the oceans through transcriptome sequencing. PLoS Biol 12:e1001889. CrossRef Medline

Khirug S, Yamada J, Afzalov R, Voipio J, Khiroug L, Kaila K (2008) GABAergic depolarization of the axon initial segment in cortical 
principal neurons is caused by the $\mathrm{Na}-\mathrm{K}-2 \mathrm{Cl}$ cotransporter NKCC1. J Neurosci 28:4635-4639. CrossRef Medline

Kim H, Ährlund-Richter S, Wang X, Deisseroth K, Carlén M (2016) Prefrontal parvalbumin neurons in control of attention. Cell 164: 208-218. CrossRef Medline

Lois C, Hong EJ, Pease S, Brown EJ, Baltimore D (2002) Germline transmission and tissue-specific expression of transgenes delivered by lentiviral vectors. Science 295:868-872. CrossRef Medline

Mahn M, Prigge M, Ron S, Levy R, Yizhar O (2016) Biophysical constraints of optogenetic inhibition at presynaptic terminals. Nat Neurosci 19:554-556. CrossRef

Mahn M, Gibor L, Cohen-Kashi Malina K, Patil P, Printz Y, Oring S, Levy R, Lampl I, Yizhar O (2017) High-efficiency optogenetic silencing with soma-targeted anion conducting channelrhodopsins. bioRxiv. CrossRef

Mardinly AR, Oldenburg IA, Pégard NC, Sridharan S, Lyall EH, Chesnov K, Brohawn SG, Waller L, Adesnik H (2018) Precise multimodal optical control of neural ensemble activity. Nat Neurosci 21:881-893. CrossRef Medline

Matasci N, Hung LH, Yan Z, Carpenter EJ, Wickett NJ, Mirarab S, Nguyen N, Warnow T, Ayyampalayam S, Barker M, Burleigh JG, Gitzendanner MA, Wafula E, Der JP, dePamphilis CW, Roure B, Philippe H, Ruhfel BR, Miles NW, Graham SW, et al. (2014) Data access for the 1,000 Plants (1KP) project. Gigascience 3:17. CrossRef Medline

Maurice N, Liberge M, Jaouen F, Ztaou S, Hanini M, Camon J, Deisseroth K, Amalric M, Kerkerian-Le Goff L, Beurrier C (2015) Striatal cholinergic interneurons control motor behavior and basal ganglia function in experimental parkinsonism. Cell Rep 13:657666. CrossRef Medline

Mauss AS, Busch C, Borst A (2017) Optogenetic neuronal silencing in Drosophila during visual processing. Sci Rep 7:13823. CrossRef Medline

Mohamed GA, Cheng RK, Ho J, Krishnan S, Mohammad F, ClaridgeChang A, Jesuthasan S (2017) Optical inhibition of larval zebrafish behaviour with anion channelrhodopsins. BMC Biol 15:103. CrossRef Medline

Mohammad F, Stewart JC, Ott S, Chlebikova K, Chua JY, Koh TW, Ho J, Claridge-Chang A (2017) Optogenetic inhibition of behavior with anion channelrhodopsins. Nat Methods 14:271-274. CrossRef Medline

Nack M, Radu I, Gossing M, Bamann C, Bamberg E, von Mollard GF, Heberle J (2010) The DC gate in channelrhodopsin-2: crucial hydrogen bonding interaction between $\mathrm{C} 128$ and D156. Photochem Photobiol Sci 9:194-198. CrossRef Medline

Parker KL, Kim Y, Alberico SL, Emmons EB, Narayanan NS (2016) Optogenetic approaches to evaluate striatal function in animal models of Parkinson disease. Dialogues Clin Neurosci 18:99-107. Medline

Price GD, Trussell LO (2006) Estimate of the chloride concentration in a central glutamatergic terminal: a gramicidin perforated-patch study on the calyx of Held. J Neurosci 26:11432-11436. CrossRef

Raimondo JV, Kay L, Ellender TJ, Akerman CJ (2012) Optogenetic silencing strategies differ in their effects on inhibitory synaptic transmission. Nat Neurosci 15:1102-1104. CrossRef Medline

Sineshchekov OA, Govorunova EG, Li H, Spudich JL (2015) Gating mechanisms of a natural anion channelrhodopsin. Proc Natl Acad Sci USA 112:14236-14241. CrossRef Medline

Sineshchekov OA, Li H, Govorunova EG, Spudich JL (2016) Photochemical reaction cycle transitions during anion channelrhodopsin gating. Proc Natl Acad Sci USA 113:E1993-E2000. Medline

Steck K, Walker SJ, Itskov PM, Baltazar C, Moreira JM, Ribeiro C (2018) Internal amino acid state modulates yeast taste neurons to support protein homeostasis in Drosophila. Elife 7:e31625.

Takahashi N, Oertner TG, Hegemann P, Larkum ME (2016) Active cortical dendrites modulate perception. Science 354:1587-1590. CrossRef Medline

Wei YC, Wang SR, Jiao ZL, Zhang W, Lin JK, Li XY, Li SS, Zhang X, $\mathrm{Xu} \mathrm{XH}$ (2018) Medial preoptic area in mice is capable of mediating sexually dimorphic behaviors regardless of gender. Nat Commun 9:279. CrossRef Medline

Wiegert JS, Mahn M, Prigge M, Printz Y, Yizhar O (2017) Silencing neurons: tools, applications, and experimental constraints. Neuron 95:504-529. CrossRef Medline

Wietek J, Wiegert JS, Adeishvili N, Schneider F, Watanabe $H$, Tsunoda SP, Vogt A, Elstner M, Oertner TG, Hegemann P (2014) Conversion of channelrhodopsin into a light-gated chloride channel. Science 344:409-412. CrossRef Medline

Wietek J, Beltramo R, Scanziani M, Hegemann P, Oertner TG, Simon Wiegert J (2015) An improved chloride-conducting channelrhodopsin for light-induced inhibition of neuronal activity in vivo. Sci Rep 5:14807. CrossRef

Wietek J, Rodriguez-Rozada S, Tutas J, Tenedini F, Grimm C, Oertner TG, Soba P, Hegemann P, Wiegert JS (2017) Anionconducting channelrhodopsins with tuned spectra and modified kinetics engineered for optogenetic manipulation of behavior. Sci Rep 7:14957. CrossRef Medline

Xu T, Huo J, Shao S, Po M, Kawano T, Lu Y, Wu M, Zhen M, Wen Q (2018) Descending pathway facilitates undulatory wave propagation in Caenorhabditis elegans through gap junctions. Proc Nat Acad Sci USA 115:E4493-E4502.

Zhang F, Wang LP, Brauner M, Liewald JF, Kay K, Watzke N, Wood PG, Bamberg E, Nagel G, Gottschalk A, Deisseroth K (2007) Multimodal fast optical interrogation of neural circuitry. Nature 446:633-639. CrossRef Medline 